
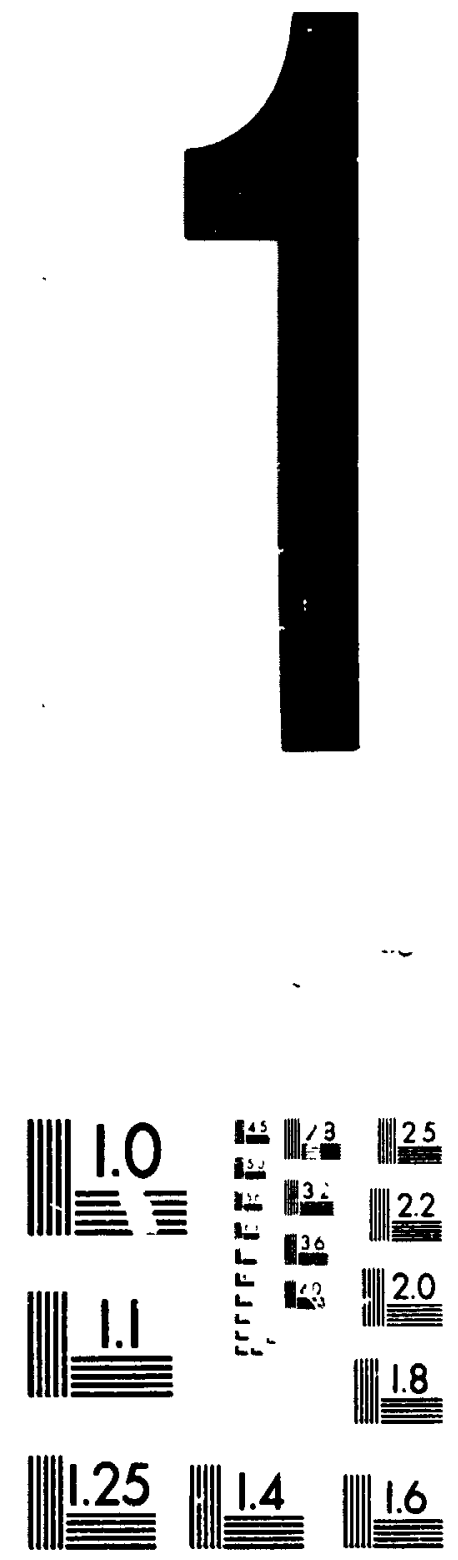

MICROCOPY RESO:UTIOIN TEST CH.ART

NATIONAL BUREAU OF STANDARUS

STANDARL REFERENCE MATERIAL 1010a

(ANSI and ISO TEST CHART No 2) 


\section{Aty National Library ol Canada}

Canadian Theses Service

Ottawa. Canada

KIA ON4
Bibliotheque nationale du Canada

\section{Service des thèses canadiennes}

\section{NOTICE}

The quality of this microform is heavily dependent upon the quality of the original thesis submitted for microfilming. Every effort has been made to ensure the highest quality of reproduction possible.

If pages are missing. contact the university which granted the degree.

Some pages may have indistinct print especially if the original pages were typed with a poor typewriter ribbon or if the university sent us an inferior photocopy.

Reproduction in full or in part of this microform is governed by the Canadian Copyright Act. R.S.C. 1970. c. C-30, and subsequent amendments.

\begin{abstract}
AVIS
La qualité de cette microlorme dépend grandenient de la qualite de la thèse soumise au microfilmage Nous avons, tout fait pour assurer une qualité supérieure de reproduc tion.

S'll manque des pages, veuillez communiquer avec l'université qui a conléré le grade.

La qualité dimpression de certaines pages peut lassser a désirer, surtout sı les pages originales ont èté dactylogra? phiées à l'aide d'un ruban usé ou sı l'universılé nous a lall parvenir une photocople de qualite intérieure
\end{abstract}

La reproduction, mème partielle, de celte microforme eni soumise à la Loi canadienne sur le droit diauteur. ShRC 1970. c. C-30, et ses amendements subsequents. 


\title{
ACID PRECIPITATION, FEMALE QUALITY, AND PARENTAL INVESTMENT OF COMMON GOLDENEYES
}

\author{
by \\ Mark Laurence Mallory

\begin{abstract}
A thesis submitted to the
Faculty of Graduate Stuc ies and Research

in partial fulfillment of

the requirements for the degree of
\end{abstract} \\ Master's of Science \\ Department of Biology \\ Carleton University \\ Ottawa, Ontario \\ March, 1991 \\ copyright \\ 1991, Mark Laurence Mallory
}


Canadian Theses Service Service des theses canadiennes

Ottawa. Canada

KIA ONA

The author has granted an irrevocable nonexclusive licence allowing the National Librery of Cenada to reproduce, ben, distribute or sell copies of hisher thesis by any means and in any form or format, making this thesis avallable to interested persons.

The author retains ownership of the copyright in his/her thesis. Neither the thesis nor substantial extracts from it may be printed or otherwise reproduced without his/her permission.
L'auteur a accordé une licence irrévocable et non exclusive permettant a la Bibliothóque nationale du Canada de reproduire, preler. distribuer ou vendre des copies de sa these de quelque manière et sous quelque forme que ce soit pour mettre des exemplaires de cette thèse à la disposition des personnes intéressées.

L'auteur conserve la proprièté du droit d'auteur qui protége sa thése. Ni la thèse ni des extraits substantiels de celle-ci ne doivent etre imprimés ou autrement reproduits sans son autorisation. 
The undersigned hereby recommend to the Faculty of Graduate Studies and Research acceptance of this thesis

"ACID PRECIPITATION, FEMALE QUALITY,

\section{AND PARENTAL INVESTMENT OF COMMON GOLDENEYES"}

submitted by Mark Laurence Mallory, B.Sc.

in partial fulfillment of the requirements for

the degree of Master of Science

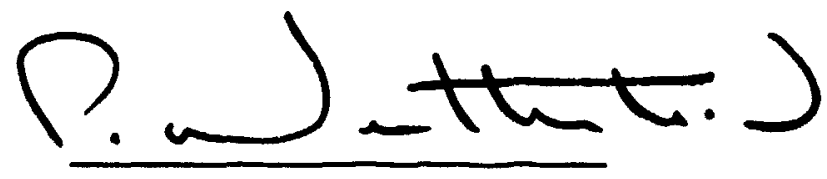

Thesis Supervisor

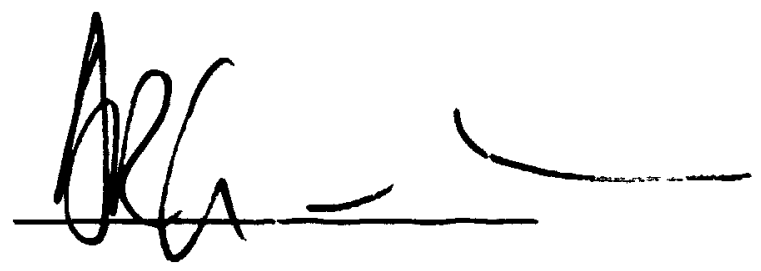

Chair, Department of Biology

Carleton University

1991 


\begin{abstract}
I examined whether habitat changes resulting from acid precipitation influciliced the reproductive effort and pertormance of female common goldencyes (Buciphliali! clanqula). Goldeneyes preferred fishless wetlands as foraging and nesting sites. Daypite this preference, females that were in better physical condition prior to egg-langing did not obtai,i nest sites on higher quality wetlands, and a considerable number of females chose nest boxes located on isolated wetlands containing fish even thugh llest buces on fishless wetlands remained available. Females nesting on fishless wetlands also produced clutches of greater mass, spent more time each day incubating their clutches, and completed incubation in relatively poorer condition than females nesting on other wetlands. Thus, goldeneyes appear to adj'st their reproductive effort and behaviour to take advantage of habitat changes resulting from acid precipitation.
\end{abstract}




\section{Acknowledgements}

As part of a long-term research program, this project can truly be called a cooperative effort. For this reason, I have many people l'd like to thank.

First and foremost. I am indebted to Pat Weatherhead who provided the conceptual framework for this study, as well as the encouragement and support necessary for its completion. He has adeptly deciphered my questions (and manuscripts!) and provided valuable insight on them, and his ability to collect the elusive lesser scaup (Aytha affinis) and common merganser (Mergus meryanser) during migration defy description. My only regret is that 1 never beat him at squash. Thanks for everything Pat.

I also wish to thank Don McNicol for providing the opportunity to conduct this research, and for his logistic and financial support through seven field seasons at Wanapitei. As my friend, colleague, and project incubator, I hope he finds this return on his investment worthwhile.

Every graduate student needs a durable and reliable household appliance to take to the field. Russ Walton served as the perfect "Toaster" for this project. It would have been impossible to collect even half of my data without his resourcefulness and patience. Thanks Russ - your reward is a godfathership!

I am deeply grateful to Mark Wayland for his help in the field and for helping with my seemingly endless questions on statistics. Thanks as well to Pete Blancher who endured similar conversations, and who first suggested the possibility of using the electronic monitoring equipment. It would have been tough to survive the last two field 
seasons without Don "Waakk" Morgan and Bob Webster and their dedicattion (o) extracurricular activities.

Thanks to the members of my thesis committee. Hans Dimminl and Sicult Findlay, for their valuable comments and suggestions at warious stages of the profect.

I thank past and present members of the Weatherhead lab, including frallices Barry, Kev Dufour, Drew Hoysak, Pete Hurd. Sue McRae, Karen Metz, Kent Prior, lan Robertson, Steve Scribner, and especially Dave Shutler for all of their help and/or distractions during my stay at Carleton. Tean team team!' I wish all of them the best in their future endeavours.

The folks at Armstrong Monitoring Incorporated, particularly Don Segall. Patt Heise, Brian White and Larry Armstong, provided a wealth of help in designing and constructing my monitoring systems, for which I am truly thankful. Thanks also fo Harry Lumsden for letting me use his equipment and some of his unpublistied dilli.

Thanks to NSERC, the Canadian Wildlite Service, the Workd Wildlife Fund, and Noranda Inc. for their tinancial support. I also thank the people at Paul Wisner alld Associates for providing me with consulting work on a tlexible schedule.

I am deeply grateful to my father, Dave Mallory, for his help in the field and in designing monitors, and to my mother, father, siblings, and my new set of parents for their support and love.

Finally, I wish to thank my wife Carolyn for all of her encouragement, pallence and love through two lonely field seasons and the time in the lab, and to my son Conor, to whom I dedicate this thesis. 
Acceptance Sheet

Abstract

Acknowledgements

i:

iii

iv

Table of Contents

vi

List of Tables

List of Figures

vii

ix

General Introduction

General Methods

CHAPTER ONE: $\quad$ Pre-incubation activity and nest site selection of breeding common goldeneyes

Introduction

Methods

Results 26

Discussion

CHAPTER TWO: Effects of habitat quality and female quality on common goldeneye reproductive effort

Introduction

Methods

Results

Discussion

CHAPTER THREE: Effects of habitat quality and female quality on common goldeneye reproductive behaviour

Introduction

Methods

Results

Discussion

General Discussion 


\section{LIST OF TABLES}

Table

Title

Page

1-1 Comparison of the number of breeding goldeneye pairs observed prior to incubation on all wetlands or experimental wetlands lacking or containing tish.

1-2 Comparisons of the proportions of time spent foraging. resting, or in combined positive activities by hens observed on wetlands with no other pairs present $(\underline{N}=14)$ or with one or more other pairs present $(\underline{N}=15)$ (MannWhitney $\underline{U}$ tests).

1.3 Annual availability and use of nest buxes by goldeneyes and other species in the study area

1.4 Comparison of goldeneye box occupancy in 1989 or $19(9)$ on wetlands lacking or containing fish $\left(\underline{X}^{2}=6.6\right.$, $\mathrm{df}=1, \mathrm{P}=0.01)$.

1.5 Habitat and nest box characteristics (mean [SE]) of experimental wetlands lacking or containing fish (MannWhitney $\underline{U}$ tests).

1.6 Habitat and nest box characteristics (mean [SE]) of occupied and unoccupied nest boxes on wetlands lacking or containing fish (Mann-Whitney $\underline{U}$ tests).

1.7 Summary of the stepwise discriminant function analysis performed on nest box characteristics used and unused hy common goldeneyes in 1989 or 199 (1).

1-8 Comparisons of goldeneye box occupancy in year $j$ in relation to occupancy of the box in year $j$ - 1 based on data collected between 1987 and 1990.

1.9 Comparison of mean (SE) estimated prelaying mass of female goldeneyes nesting on four different types of habitats (ANCOVA, $E=0.09$, df $=3,20, \underline{P}=0.96$; covariate nest initiation date). 
2.1 Mean clutch sizes for common goldeneyes in each year of observation.

2-2 Mean Julian date of nest initiation for common goldeneyes in each year of observation.

2.3 Mean egg mass (g) and mean clutch mass (g) for complete common goldeneyes clutches in 1989 and $19 \% 1$.

2.4 Comparisons of breeding variables of experienced and inexperienced female common goldeneyes at Wanapitei (Mann-Whitney $\underline{U}$ tests).

2.5 Comparison of mean $( \pm)$ initiation date, clutch size, egg mass and clutch mass of goldeneyes nesting in four types of habitats.

3-1 Means ( $\pm \mathrm{SE}$ ) of daily time spent on the nest, length of recess breaks, and number of daily recess breaks for female goldeneyes nesting on habitats of differing quality.

3.2 Meins $( \pm S E$ ) of weekly incubation mass of female goldeneyes nesting on wetlands differing in quality.

3-3 Mean ( \pm SE) hatching success of clutches (that hatched at least one egg) on wetlands of differing quality. 


\section{LIST OF FIGURES}

Figure

Title

Page

1 A schematic diagram of the load cell monitoring system.

2 A schematic diagram of the balance monitoring system.

2-1 Relationships between a) nest initiation date and clutch mass, b) nest initiation date and estimated prelaying miss of female goldeneyes, and c) clutch mass and estimated prelaying mass of temale goldeneyes.

3-1 The relationship between the amount of time spent off the nest each day and incubation date for each habitat category.

3.2 The pattern of weight change for incubating common goldeneyes. 


\section{GENERAL INTRODUCTION}

\section{Acid precipitation}

Acid precipitation has caused extensive environmental damage to aquatic ecosystems in eastern North America and Europe (Haines 1981). Considerable research has been conducted on aquatic organisms to determine the impacts of acid precipitation on aquatic food webs. Results of these studies indicate that acidification of aquatic habitats and the associated changes in water quality (e.g. increased trace metal concentrations) have led to altered composition, distribution, and abundance of aquatic biota (reviewed in McNicol et al. 1987). One of the most intensively studied effects on aquatic biota has been the susceptibility of various tish species to reduced lake pH (e.g. Beamish and Harvey 1972, Beamish 1974). When lake acidity declines below the survival threshold for resident fish species, fish populations are lost. The loss of fish in wetlands removes the top predators trom aquatic ecosystems: predatory macroinvertebrates usually replace tish as the top predators and thus they are typically abundant in acidic lakes (Eriksson et al. 1980, Bendell and McNicol 1987a). In turn. increases in predatory invertebrate populations cause substantial alterations to the entire aquatic invertebrate assemhlage (Eriksson et al. 1980). Changes in aquatic invertebrate assemblages may also occur through the direct loss of many acid-sensitive species of invertebrates (e.g. Camphell and Stokes 1985).

Current research indicates that acid precipitation not only puts aquatic biota at risk, but that bird species that depend on aquatic biota may also be aftected. For 
example, altered distributions of some bird populations have heen linked (1) (hanges in aquatic fcod webs caused by acid rain (Eriksson et al. 1980. DesGranges and Darveau 1985, McNicol et al. 1987). Similarly, declines in common loon (Giavia immer) populations in Ontario are attributable to the loss of tish populations in many alcidic lakes (Alvo et al. 1988). Experimental studies have also demonstrited that. for ecrtilin species of waterfowl, duckling growth and survival is lower on acidic wetlands heciluse of poor food quality (Rattner et al. 1987. McAuley and Longcore 1968). Furthermure. direct toxic effects of increased aluminum and decreased calcium availability in atidic wetlands contribute to eggshell abnormalities of passerines in Sweden (Nyholm and Myhrberg 1977, Nyholm 1981), the Netherlands (Drent and Woldendorp 1989), Willes (Ormerod et al. 1988), and Canada (Glooschenko et al. 1986), although this does not necessarily lead to reduced breeding success.

While researchers continue to demonstrate effects of acid precipitition on hird populations, few studies have identified the mechanisms by which these effects arc achieved. However, two recent studies have examined potential sublethil effects of alcid precipitation on the reproductive success of small passerines that rely on aquatic habitats for breeding. Research by Ormerod et al. (in press) in Wales has demonstrated that female dippers (Cinclus cinclus) nesting near acidic streims initiate nests later, lay fewer eggs, and produce fewer young than females nesting on circumneutral streams. These results were partially attributable to the poorer prebreeding condition of females using acidic streams, and the reduced capacity of these females to satisfy their energetic requirements for breeding prior to nest initiation on 
this habitat (O'Halloran et al. 1990). Females using acidic streams spent more time foraging and less time resting and storing nutrient reser.s tor breeding, presumably because invertebrate prey in acidic streams were less abundant and were poor quality prey (O'Halloran et al. 1990). In a similar study in Ontario, Canada, Blancher and McNicol (1988) found that female tree swallows (Tachycineta bicolor) nesting near acidic wetlands laid fewer eggs and fledged fewer young than females nesting near nonacidic wetlands. They suggested that lower quality and/or less abundant prey in acid wetlands contributed to reduced breeding success for swallows relying on these sites for invertebrate prey. Thus, both of these studies suggest that changes in wetland quality resulting from acid precipitation affect reproductive effort and performance of females breeding on habitats of differing quality. Because many waterfowl species breed on lakes and wetlands in regions severely affected by acid precipitation, it is likely that a similar mechanism operates on ducks nesting on or near acidic wetlands.

\section{Parental investment}

Trivers (1972) introduced the concept of parental investment to describe behaviours and contributions by parents that enhance the survival of existing offspring at the expense of the potential for producing future oftspring. Triver's framework did not consider mating effort (e.g. courtship, territory defense) as part of parental investment, although costs associated with mating may require substantial investment (see Anderson 1984). Natural selection should favour investment decisions that maximize lifetime reproductive success (Trivers 1972, Dawkins and Carlisle 1976, 
Montgomerie and Weatherhead 1988). For each breeding attempt. investme'tu by the parents will be influenced by both the quality of the parents and the quallity of the breeding habitat. For example, recent evidence indicates that femiles of malny passerine species adjust their investment in relation to both paremtal quality ( $c . \mathrm{g}$. Högstedt 1980, Slagsvold and Lifjeld 1988, 1990) and habitat quality (e.g. Hog̣stedt 1981, Arcese and Smith 1988). This pattern is also evident in many other types of birds, such as owls (e.g. Hörnfeldt and Eklund 1990), grouse (Naylor and Bendell 1989), and seabirds (e.g. Amundsen and Stokland 1990).

Waterfowl species vary significantly in how they allocate reproductive resources (Kear 1970). Some species lay two or more large ciutches annually but provide intle parental care for their ducklings, while other species lay a single, small clutch and provide extensive care for their brood. Watertiowl typically lay large clutches of entergydense eggs (King 1973, Ricklefs 1974), so the greatest annual investment in offispring is the time and resources used in producing and incubating a clutch. This is particularly true for most temperate-nesting, North American ducks which provide relitively little post-hatching parental care (Kear 1970, Nudds 1980, Eadie and Lumsden 1985).

\section{The common goldeneye (Bucephala clangula)}

The common goldeneye (Tribe Mergini) is a medium-sized, diving duck that breeds in the boreal forest of North America (Bellrose 1980). Goldeneyes spend the winter as far north as possible, apparently limited by the availability of open water. Pairing occurs over the winter (Afton and Sayler 1982), and goldeneyes arrive on the 
breeding grounds as soon as the ice breaks up on boreal lakes and wetlands. On the breeding grounds, male goldeneyes defend a feeding territory for their mate (Savard 1984), which provides her with a disturbance-free zone to forage for prey crucial to egg production (Savard 1988). The male usually abandons the female early in the incubation period (Bellrose 1980).

Several characteristics of common goldeneye breeding biology make this an ideal species in which to examine the responses of breeding females to differing habitat quality caused by acid precipitation. First, goldeneyes breed in the boreal torest of eastern Canada, an area heavily affected by acid precipitation (McNicol et al. 1987). Second, during the breeding season, female goldeneyes forage primarily for protein-rich invertebrates (Eadie and Keast 1982, Bendell and McNicol unpubl.). Thus, goldeneye breeding site quality should vary significantly, because acid precipitation causes loss of fish populations that creates large variation in invertebrate abundance in wetlands (Eriksson 1979b, 1983). Third, goldeneyes are cavity-nesters and readily use man-made nest boxes (Bellrose 1980), so potential nest sites and breeding site quality can be manipulated. Finally, goldeneyes usually make only one breeding attempt per year and rarely renest (Zicus 1950). Female goldeneyes provide relatively little care for the young after hatch (Bellrose 1980), so measurements of resource allocation in eggs and incubaticin performance are a good index of total annual parental investment.

\section{Study objectives}

Several authors have suggested that while piscivorous watertowl should be 
affected negatively by acid precipitation. insectivorous waterfiowl. and especially (ummun goldeneyes, may derive short-term benefits from acid precipitatum. Severall studies hale demonstrated that fïshless wetlands have significantly more abundan! and diverse aquatic invertebrate assemblages than wetlands containing tish (Erikssun et :I. 19si). Eriksson 1979b, 1983, Bendell and McNicol 1987a,b, unpubl. MS., Mallory cl all. unpubl. MS). At any one sampling period, some wetlands containing fish may have more abundant invertebrate populations than some fishless wetlands, due to the composition of the fish assemblage. and seasonal and annual variation in invertebrate abundance (e.g. Mallory et al. unpubl. MS. D. K. MiNicol pers. comm.). However, Mallory et al. (unpubl. MS) have shown that using the presence or absence of tish (as an index of aquatic invertebrate abundance) to assess wetland quality is as reliable as using numbers of invertebrates alone. Research has also shown that goldencyes prefer wetlands (or lake regions) where tïsh are absent (Eriksson 1979), 198.3, Eadies and Keast 1982), supporting the contention that goldeneyes assess wetland quality based on the presence or absence of fish. Thus, goldeneyes may hencfit from acid precipitation because fishless wetlands (i.e. suitable foraging and breeding habitat) would be more abundant (Eriksson 1983, McNicol et al. 1987, DesGranges 1989). Therefore, the aim of this study is to test the hypothesis that common goldeneyes breeding in a region of Ontario heavily affected by historic and current acid deposition benefit by nesting on tishless wetlands.

In Chapter one. I examine wetland use prior to incubation and nest site selection by common goldeneyes. If goldeneyes assess wetland quality by the abundance of ford 
resources and if they prefer to nest near high quality areas, then breeding pairs should forage and nest more often on fïshless wetlands (because fishless wetlands typically contain more abundant invertebrate prey; Eadie and Keast 1982, Eriksson 1983). As well, if wetland quality is beneficial to nesting females, competitively superior females should obtain boxes on the highest quality wetlands.

In Chapter two, I assess the effects of habitat quality and female quality on goldeneye reproductive effort. The resources waterfowl contribute to egg production is intluenced by the amount of lipid reserves females store prior to egg-laying (female quality) (e.g. Ankney and Afton 1988) and the amount of protein-rich food resources available near the breeding wetland (habitat quality) (e.g. Bengston 1971). Female goldeneyes that have larger nutrient reserves or that select nest sites on tishless wetlands with suitable, nearby brood-rearing wetlands should contribute more resources in their clutch, because the anticipated survival of offspring raised on these wetlands should be relatively high (Eriksson 1979a).

In Chapter three. I examine how the quality of a breeding wetland and the condition of a female goldeneye at the initiation of incubation affect their incubation schedule or pattern of weight change. On wetlands where the return on parental investment in offspring is expected to be high, females should take the greatest risks to enhance hatching success. Thus, I expected females nesting on fishless, clustered wetlands and those temales heginning incubation in better physical condition to spend proportionally more time incubating their clutch, and to lose relatively more weight during incubation than temales on isolated wetlands containing tïsh. 


\section{GENERAL METHODS}

\section{Study area}

The Wanapitei study area is located $50 \mathrm{~km}$ northeist of Sudbury, Ontario at $41^{\circ}$ $55^{\prime} \mathrm{N}, 80^{\circ} 45^{\circ} \mathrm{W}$, and covers approximately $500 \mathrm{~km}^{2}$. The areal has heen heavily affected by local smelting emissions in Sudbury and from long-range transport of airborne pollutants (Jeffries 1984). Because much of the site is underlain by bedrock with low buffering capacity (McNicol et al. 1987), historic and recent ancid deposition has resulted in a high proportion of lakes being acidic (Pitblado et al. 1980, McNicol et al. 1987). Approximately 250 lakes and wetlands lie within the study site boundaries; 1 restricted my study to the smaller, shallow wetlands more typicil of breeding goldeneye habitat (McNicol et al. 1987). Goldeneye nest boxes were erected on 71 of these wetlands (hereafter termed experimental wetlands) between 1966 and 1989, with a maximum of 68 available in any year. Open-water area of experimental wetlands ranged from 1.0 to 29.2 ha, as determined from aterial photographs and topographic maps, and wetland acidities varied between pH 4.19 to 7.31. Maximum watter depths ranged between $0.5 \mathrm{~m}$ to more than $10 \mathrm{~m}$.

\section{Water chemistry}

Littoral grab samples of water were collected in August 1990 for 64 of the 71 experimental wetlands (data for the seven other wetlands were collected in Octoher of previous years (McNicol et al. 1987)). Water samples were immediately cooled and 
analysis was performed within 7 days of collection at the Great Lakes Forest Research Centre, Sault Ste. Marie, Ontario. In this study I was only interested in potential relationships between wetland acidity and reproductive effort or pertormance, so I used $\mathrm{pH}$ as an index of general chemical conditions of each wetland. A detailed description of the chemical determination procedures is found in McNicol et al. (1987).

\section{Fish sampling}

Declines in lake $\mathrm{pH}$ resulting from acid deposition have caused damage or destruction of fish populations in this region (Beamish and Harvey 1972, Beamish 1974). Thus, the abundance of tishless wetlands at Wanapitei is largely the result of acid precipitation, although several experimental headwater wetlands located on ridge tops are fishless because their remote locations have prevented fish colonization (McNicol et al. 1987). For the purposes of this study, I scored wetlands as either lacking or containing fïsh, regardless of species composition. The standard procedure for determining fish presence in wetlands was to place five cylindrical minnow traps (baited with dog biscuits) equidistant around the shoreline of each wetland for a $24 \mathrm{hr}$ period (Rendell and McNicol 1987b). Traps were constructed of $6 \mathrm{~mm}$ wire mesh. and measured $1.0 \mathrm{~m}$ by $30 \mathrm{~cm}$ in diameter, with openings $40 \mathrm{~mm}$ in diameter at each conical end. Most wetlands were trapped in 1984, with new wetlands and samples of the original wetlands retrapped in each subsequent year of the study. 


\section{Lake isolation}

I measured distances between wetlands to the nearest sil) $\mathrm{m}$ frum alerial photographs and topographic maps. Similarly, topographic maps werc used tw ciunt the number of water bodies within a $1 \mathrm{~km}$ radius of the breeding wetland. I defined isolated wetlands as those where the distance to the nearest water body (pond. river or lake) was greater than $500 \mathrm{~m}$, and/or if there were fewer than three discrete willer bodies (regardless of size) within a $1 \mathrm{~km}$ radius of the beeding wetland. All other wetlands were considered to be clustered.

\section{Incubation monitoring equipment}

To measure the daily weight change of females, the time they spent on and ofl the nest, and the frequency of their incubation recesses, I used lwo types of remolic monitors that could be installed in the nest box and unobtrusively record fembile behaviour. The first system, termed the load cell system, is depicted in Figure 1. This system had been used previously to monitor incubation and weight change in common goldeneyes and hooded mergansers (Lophodvtes cucullatus) (L.umsden unpulh). MS). I obtained five sets of this monitoring system from the Ontario Ministry of Natturil

Resources. A load cell (composed of four strain gauges linked (1) a weighing plattorm) was calibrater and installed on the floor of an occupied nest box. A single ciable relayed both power and measurements of mass change on the platform between the Rustrak strip recorder located approximately $10 \mathrm{~m}$ behind the base of the nesting tree and the load cell. The Rustrak recorder had a full scale reading of $0.5102 .5 \mathrm{~kg}$ and 
Figure 1. A schematic diagram of the load cell monitoring system. System components are as follows: - nest box, b - eggs, c - platform, d - load cell, e - monitor housing, f - Rustrak strip recorder, 8- $12 \mathrm{~V}$ battery, $\mathrm{h} \cdot$ solar panels. 


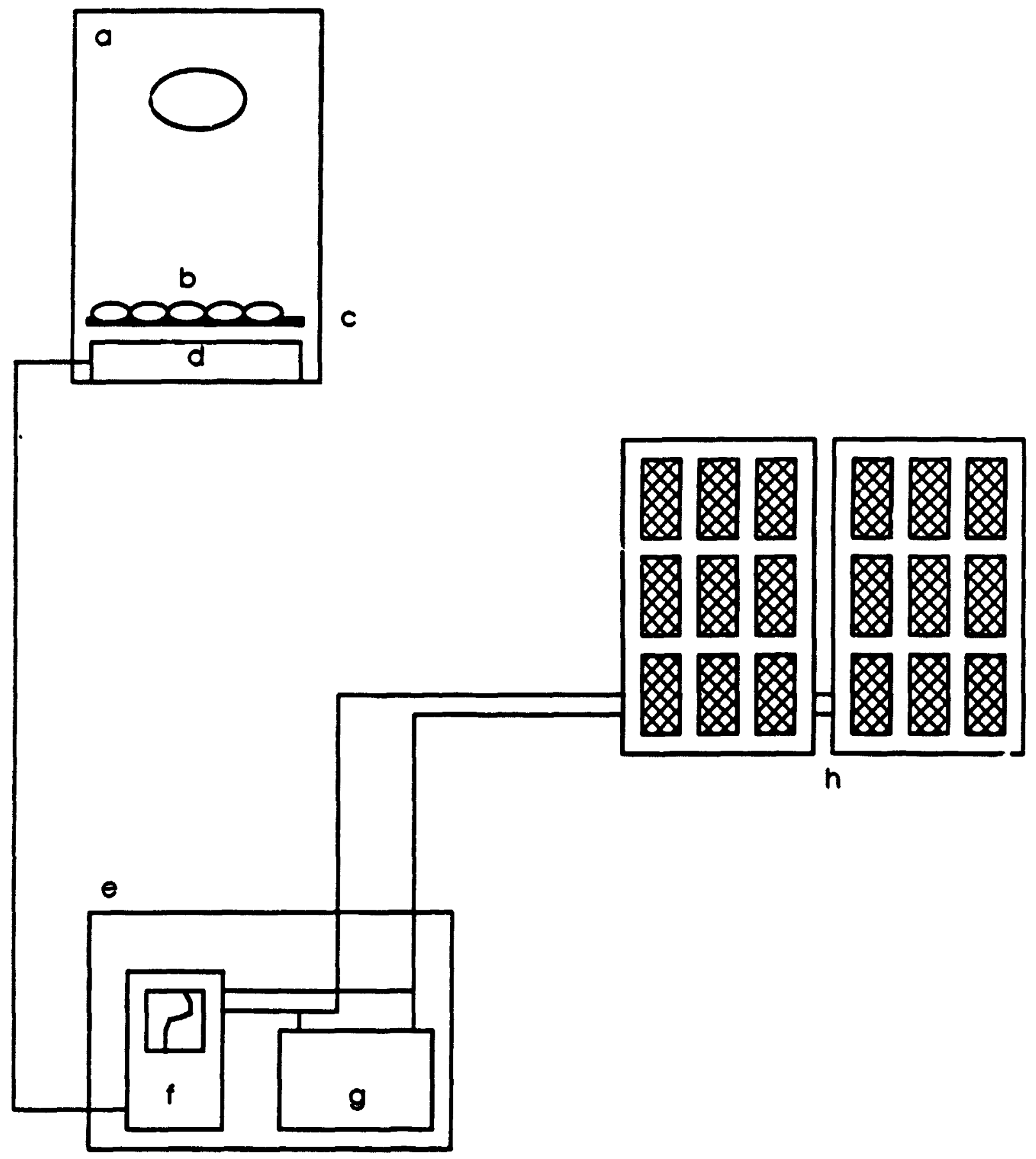


was fitted with an alternator to control current and give accurate operation from a DC $12 \mathrm{~V}$ battery. The power supply was provided by a $12 \mathrm{~V}, 24 \mathrm{~A} / \mathrm{hr}$ rechargeable battery. This battery was recharged by $t w 046 \mathrm{~cm} \times 58 \mathrm{~cm}$ solar panels, each capable of returning $1 \mathrm{~A} / \mathrm{hr}$. Installation of this system took approximately $45 \mathrm{~min}$ (two people) and required only a single small hole in the nest box for the cable to pass through. The load cell system proved very effective and accurate, but used considerable energy such that during periods of infrequent sunshine, batteries ran out of power. After the first field season this constraint was recognized, and by replacing batteries at approximately 10 day intervals, continuous incubation monitoring could be achieved. These systems recorded useful incubation data from 10 incubating temale common goldeneyes.

The second system, termed the balance system, is depicted in Figure 2. I used six sets of this monitoring system. An electronic balance, accurate to $1 \mathrm{~g}$ with a range of zero to $3.0 \mathrm{~kg}$, was installed on the tloor of an occupied nest box. Two cables were attached to the balance and protruded through small holes drilled into the nest box one provided operating power from a $12 \mathrm{~V}, 24 \mathrm{~A} / \mathrm{hr}$ rechargeable battery, and the other conveyed measurements of mass on the balance platform to a statistical printer. Both the printer and the battery were housed approximately $10 \mathrm{~m}$ behind the nest box. A small timer, powered by eight D-cell alkaline batteries, was attached to the printer, causing a recording to be printed at approximately $6.5 \mathrm{~min}$ intervals (this interval was adjustable). The printer was also powered by the rechargeable battery powering the balance. The battery was recharged by a single, $46 \mathrm{~cm} \times 58 \mathrm{~cm}, 1 \mathrm{~A} / \mathrm{hr}$ solar panel. 
Figure 2. A schematic diagrain of the balance monitoring system. System components are as follows: a - nest box, b - eggs, c - platform, d - electronic balance, e - monitor housing, 1 - timer, 8 - statistical printer, $\boldsymbol{h}$ - $12 \vee$ battery, $\mathbf{i}$ - solar panel. 


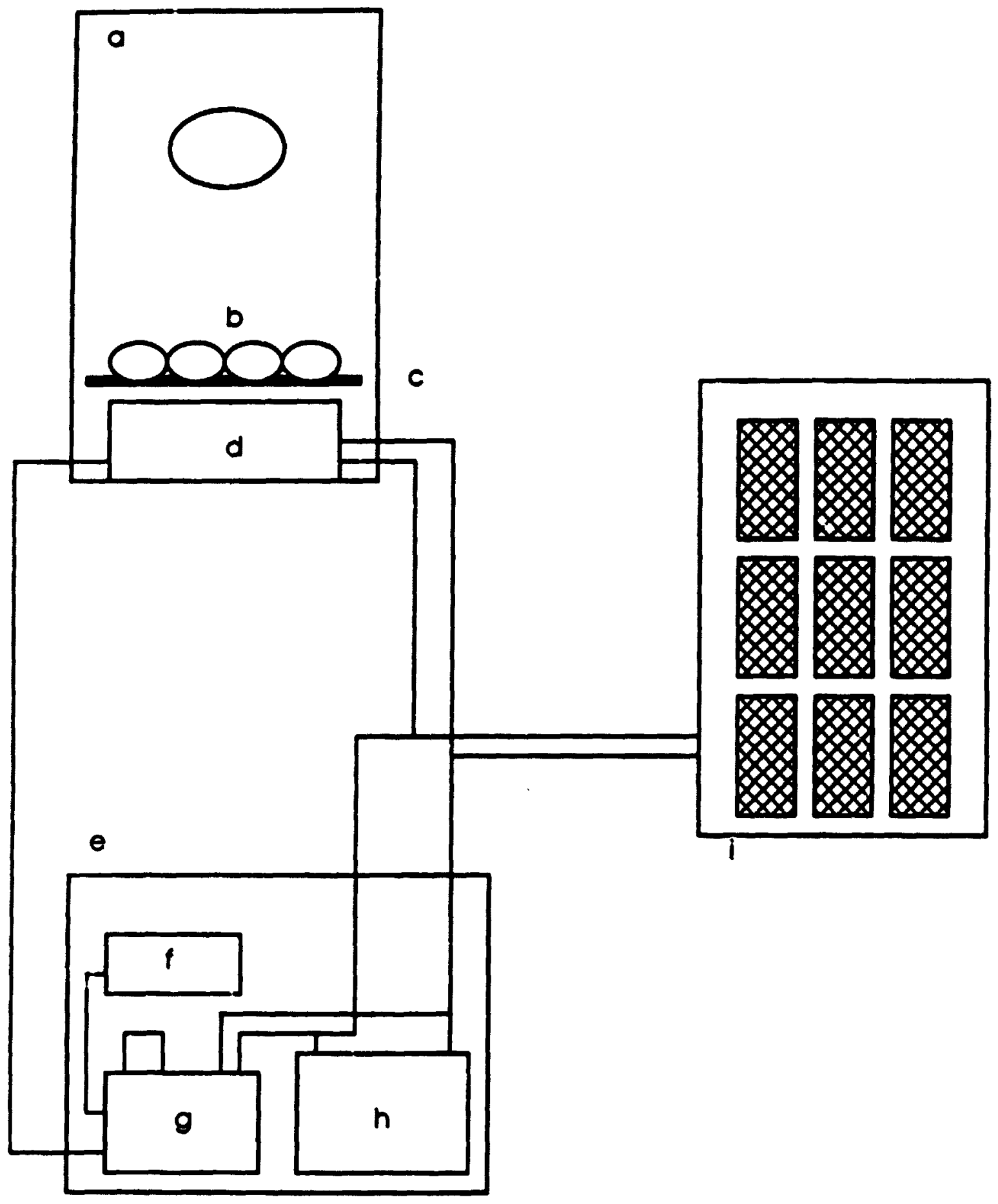


Two people could install this system in approximately 45 min. This system also proved very accurate and could run continuously tor an entire incubation period, althumgh batteries were replaced at approximately 15 day intervals. A signilicamt drawliak af this system was its apparent negative effect on developing embryos. Ot the sercill females monitored with this system, four females experienced zero percent hatching success. H. G. Lumsden (pers. comm.) found a similar effect on goldenteyes monitured with the load cell system (although I found no such effect with the same load cells). He attributed reduced hatching success to impaired development of embryos very early in incubation caused by strong electromagnetic radiation from the electronic plattorms. This explanation is plausible, since three of the four unsuccessful nests in my study were monitored from at least one day prior to incubation initiation, whereas the three successful iemales monitored with balance systems were monitored from latter in the first week of incubation. If embryos are damaged early in development by these systems, they appear to develop until late in incubation and then die. I observed live embryos in these unsuccessful clutches as late as day 26 of incubation. Beciasc (mbryo development appears to proceed until late in incubation, affected females may be unaware of the problem because their incubation behaviour was similar to that of unafiected females.

\section{Changes in female weight}

The load ceil system recorded data continuously for the duration of each day. Because the system used a Rustrak strip recorder, inaccurate weight recordings cilused 
by movement on the nest were recorded as a dot off of the line of continuouslyrecorded weight and thus were easily detected. With the balance system, weight was only recorded when there was no motion on the platform, so artifact recordings could again be identified and excluded.

I have included a detailed description of the procedure for calculating female weight in Chapter three, because female weight change during incubation is an important component of reproductive performance. However, I have used the estimated weight of temale goldeneyes prior to egg-laying as my index of female quality in all three chapters, and therefore I have included a brief description of the procedure for determining female weight in the General Methods.

The weight of a female goldeneye on each recorded day of incubation was calculated by subtracting the weight of the eggs and nest (recorded when the female was absent from the nest) from the weight of the eggs, nest and incubating female. For each day, I calculated a value termed incubation weight, which was the result of dividing each daily weight by the minimum recorded weight of a female during the entire incubation period. Incubation weight was then expressed as a percentage of that minimum weight. For instance, the incubation weight of a female that weighed $660 \mathrm{~g}$ on the second day of incubation and had a minimum recorded weight of $600 \mathrm{~g}$ would be $110 \%$.

Using values of incubation weight for each female on each recorded day of incubation, I calcuiated an equation that describes the typical pattern of weight loss for 
incubating female goldeneyes. This equation was derived from a non-lincir regression of incubation weight on incubation stage. The equation is:

$$
I=122.2-1.1(D)+0.01(D)^{2} ; r^{2}=0.57 \text {. }
$$

where $I$ is incubation weight and $\mathbf{D}$ is the day of incubation. On the first day of incubation, a typical female goldeneye is approximately $21 \%$ heavier than the lowest weight it will reach during incubation. This value is consistent with meisures of weight lost by incubating hens of other members of the tribe Mergini (reviewed in Gatti 1983).

\section{Estimation of female prelaying weight}

For most species of North American waterfowl, the weight of a female prior to egg-laying is a good indicator of female quality (e.g. Hepp et al. 1987. Ankney and Afton 1988). This pattern appears to be consistent for breeding female common goldeneyes (Lumsden unpubl. MS). Female goldeneyes were calptured on the nest during incubation by quietly approaching the nest box and blocking the entrance. The female was then gently removed from the box, weighed (to) the nearest $10 \mathrm{~g}$ with a $10(10)$ g spring balance) and measured, and equipped with plastic nasal markers (Sugden and Poston 1968) and an USFWS aluminum leg band. The stage of incubation on the day of capture was determined from the date of nest initiaticn. The weight of each femiale at the initiation of incubation was then estimated by substituting the capture weight ind incubation date into the weight loss regression derived for incubating female goldencyes (see above). The weight of a female goldeneye prior to egg-laying (prelaying mass) would have been greater than her weight at the start of incubation, since female 
waterfowl use some of their nutrient reserves (primarily lipids) to form eggs (e.g. Drobney 1980, Ankney and Afton 1988). Female common goldeneyes lose approximately $22 \mathrm{~g}$ of body mass for each egg laid (Lumsden unpubl. MS). Thus. to determine estimated prelaying weight of female goldeneyes, I added $22 \mathrm{~g}$ to the estimated weight of each female at the initiation of incubation for each egg in her clutch. Estimates of prelaying weight were only calculated for females with clutches of 10 eggs or less, because larger clutches are usually the result of nest parasitism (Chapter 2) and thus calculations based on clutch size would overestimate prelaying weight. Mean ( \pm standard error) estimated prelaying weight of temale goldeneyes nesting at Wanapitei $(875 \pm 10 \mathrm{~g})$ was higher than mean measured prelaying weight of temales nesting in an area $50 \mathrm{~km}$ east of the study site $(842 \pm 10 \mathrm{~g}$; Lumsden unpubl. MS); differences of this magnitude may be attributed to variation in habitat quality (Lumsden unpubl. MS). Nonetheless, my estimates of go: 'eneye prelaying weight are a useful index of female condition for comparing females within the Wanapitei study population. 


\section{CHAPTER ONE}

Pre-incubation activity and nest site selection

of breeding common goldencyes 


\section{Introduction}

The behaviour of breeding waterfowl between their arrival at the breeding grounds and the initiation of incubation can affect breeding success significantly.

During this period, two activities that can influence reproductive effort are the acquisition of exogenous reserves for clutch formation (e.g. Krapu 1981), and the selection of a nest site (e.g. Dow and Fredga 1985).

For temperate-nesting ducks, lipid requirements for egg-laying and incubation are obtained from endogenous reserves stored during the winter. whereas most of the protein requirements are obtained exogenously on the breeding grounds (Drobney 1980, Krapu 1981, Reinecke et al. 1982, Tome 1984, Noyes and Jarvis 1985, Hohman 1986a. Ankney and Afton 1988). Female waterfowl acquire necessary protein by spending a large proportion of their time foraging for aquatic inverteblates (e.g. Afton 1979. Drobney 1980, Krapu 1981). To facilitate the female's ability to acquire protein, the male usually establishes a territory that secures a food supply for the hen and provides her with the undisturbed feeding time critical for egg formation (e.g. Atton 1979, Savard 1988). Any factors that interfere with the ability of a hen to feed successtully will negatively influence her reproductive success.

The location and quality of nest sites can also affect reproductive success. In cavity-nesting waterfowl, the most common causes of nest failure are nest desertion by the female (e.g. Dow and Fredga 1984, Gauthier 1988), predation (e.g. Eriksson 1979a), and nest parasitism (e.g. Semel et al. 1988). If females can assess the likelihood of nest success, then they should prefer nest sites where the chances of nest failure are low. 
Studies have shown that females returning to the same nest site in successive gevirs hate greater reproductive success, beciluse they benefit from fimiliarity with proditturs allul feeding sites near the nest (see Rohwer and Anderson 1988). As will. female's selecting a new nest site prefer locations where others were successful in the provious lealr. presumably because prior success suggests safety from predators or tiaturs (c.g. weather) which lead to desertion (Dow and Fredga 1985, Gatuthicer 1985). Females may also prefer more remote or isolated nest sites, since the risks associalted with nest parasitism are reduced for these locations (Semel et al. 1988). However, ducklings hatched on isolated lakes may suffer higher mortality when travelling w brond-rearing lakes (Ball et al. 1975, Eriksson 1979a). The benefits of nesting in higher densities neiar suitable brood-rearing sites may outweigh the benefits of minimizing paraisitism risk. so females may prefer boxes situated in higher densities (e.g. lucated on clustered wetlands).

I examined the effects of habitat quality and female quality on pre-incubattion activities and nest site selection of breeding female common goldeneyes. Goldencyes are primarily insectivorous (Eriksson 1979b, Eadie and Keast 1982, Bendell and McNicol unpubl. MS), and prefer to feed in locations with few or no fish (Eriksson 1979b, 1983, Eadie and Keast 1982) hecause tishless wetlands usually have a higher abundance of aquatic invertebrates (Eriksson 1983, Bendell and McNicol 1987:1). Thus, wetlands without fish should be assessed as higher quality. I predicted that females foraging for invertebrates prior to incubation would use fishless wetlands more ofien than wetlands containing fïsh. As well, females using fishless wetlands should spend 
more time in activities conducive to egg-formation (e.g. feeding, resting) than females on wetlands containing fish, particularly on sites where intraspecific competition for food resources is small. I also predicted that goldeneyes would prefer (o) nest in boxes erected on fishless wetlands rather than boxes on wetlands containing fish. and that nest boxes used the previous year would be preferred to previously unused boxes. As well, since competition for nest sites in the genus Bucephala can be intense (Savard 1984, 1988, Gauthier 1988), I expected that higher quality females (i.e. heavier females) would acquire nest sites on better wetlands (i.e. fishless). Finally, because ducklings hatched from nests located on isolated sites may experience greater brood mortality when travelling to rearing lakes (Eriksson 1979a), I predicted that females would prefer nest boxes located on clustered wetlands. 


\section{Methods}

\section{Wetland classification}

I based wetland classification on two criteria: fish presence (regardless of species composition), and proximity to neighbouring wetlands (see General Methods). Lour wetland categories were established: isolated wetlands containing tish, isolatted wollands lacking fish, clustered wetlands containing tish, and clustered wetlands lacking tish.

\section{Activity Buduets}

Data were collected in 1989 and 1990 on marked and unmarked common goldeneye pairs at a time when most pairs were preparing for egg-laying (1 Ming 11 I6 May). Marked pairs were identified by the returning hen which had been ecyuippred with a plastic, uniquely-coloured nasal saddle (Sugden and Poston I9(2\$) one or Iwo years previously. Hens of unmarked pairs were assumed to be new to the site (probably breeding for the first time). Since I was primarily interested in the effects of wetland quality and competition with other pairs on breeding activities, it wiss not important to know the identity of each pair. To minimize potentisl bials crealted hy repeated observations of the same pair, I visited a wetland only once in a dily, and I averaged values of time spent in various activities for all observations on the salme pair. I was confident that repeated observations of an unmarked pair on the same wetland were on the same pair for two reasons. First, most wetlands at Winapitei were small. supporting a maximum of three pairs, but usually one or two. Fortunately, one of the 
pairs often contair.ed a marked hen. Second, goldeneyes are strongly territorial during the prelaying and laying stages (Savard 1984,1988 ), so it was unlikely that a pair would move once they had established a territory.

Observations of pairs were conducted between $07(0) \mathrm{hrs}$ and $1930 \mathrm{hrs}$ DST. and consisted of continuously recorded 30 min sampling periods. I defined the number of pairs on a wetland as the maximum number of pairs observed during the sampling period. Recordings were made from concealed locations in the vegetation surrounding the wetlands, at distances ranging between $20 \mathrm{~m}$ and $120 \mathrm{~m}$. Usually two observers were used: one observer recorded the pairs' activity with a VHS video camera while the other watched with a $40 \mathrm{X}$ spotting scope and described the activity (in case the camera lens was obscured by vegetation). In a few cases, observations were recorded by one person using either technique. I classified activities into 6 categories: 1) feeding (diving); 2) resting (loafing, sleeping or preening); 3) swimming: 4) alert; 5) agonistic interaction (e.g. threat displays, swimming chases, aerial pursuit); 6) out of sight. I calculated the proportion of time hens spent in each activity based on the amount of time the hen was actually observed in the 30 min period. In situations where 1 was confident that I had recorded activities of the same pair on different dates (but on the same wetland), I calculated mean values for each activity using all activity budgets on that pair. I considered time spent feeding or resting to have a positive impact on energy available for egg formation (hereafter termed positive activity), since these activities involved collection and storage of energy for egg production. However, time spent alert, swimming or in social interactions was considered to have a negative impact 
on energy available for egg formation. because these activities required energy that could otherwise be used in egg procuction.

Nest Box Use

A nest box considered used if at least one goldeneye egg was laid in the box. Boxes that were unsuitable for nesting (e.g. the door was open, or the box wiss kmocked down or destroyed) were excluded from analyses of nest box choice, and boxes thitl had been unsuitable for nesting in the previous year were excluded from the analysis of box choice in relation to previous occupancy. Nest sites that were used by the same fembile in successive years were entered only once in any comparison. since choice in a successive year may have been based more on experience than site characteristics. Since goldeneyes are early-nesting, aggressive, and generally dominimt to competitur species (e.g. Savard 1984), I treated nest boxes occupied by other species is availiable and unused by goldeneyes for that year. However, goldeneyes prospecting for mest sites may assess successful nests of conspecifics and other species as indicitive of high site quality (Eadie and Gauthier 1985). Thus, in the analysis of box choice in relation to previous occupancy, I treated nest boxes used in the previous year by other speciess as used.

\section{Habitat Characteristics}

When each box was erected, I sampled the habitat surrounding the site. In addition to determining whether the wetland adjacent to the box contained fish, ninc other variables were measured: the height of the box from the water level to the hole 
entrance (BOXHT); the distance from the box to the shoreline (DISTH20); the circumference of the nest box tree at breast height $(\mathrm{CBH})$; the direction the box entrance faced (COMPASS); the number of separate water bodies (lakes, streams. rivers) within a $1 \mathrm{~km}$ radius of the box (NLK1K); the $\mathrm{pH}$ of the wetland $(\mathrm{pH})$; the area of open water on the breeding wetland (AREA); the distance to the i.carest water body (NEARLK); and the distance to the nearest nest box (NEARBX). I excluded COMPASS data from all analyses for two reasons. First, Lumsden et al. (1980) had previously demonstrated that goldeneyes nesting in an area $50 \mathrm{~km}$ to the east did not prefer boxes oriented towards certain directions. Second, any potential effect of box orientation on nest site selection by Wanapitei goldeneyes was likely to be very small compared to the effects of wetland quality and nest site competition, because only one box was usually available on a wetland. All remaining variables except AREA. NEARLK, and NEARBX were normally distributed (Kolmogorov Smirnov Tests, all P's $>$ (1.05). I normalized AREA data by $\log$ transformation ( $\log _{10}$ AREA), NEARLK data by inverse transformation (1/NEARLK), and NEARBX data by square root transformation ( $\sqrt{\text { NEARBX }}$.

I considered wetlands to contain tish if any tish were present, regardless of species (see General Methods). To determine whether other site characteristics influence nest site choice of common goldeneyes, I performed a discriminant function analysis (DFA) within wetlands with and without fish to characterize the nesting habitat of boxes that were used and unused by common goldeneyes in 1989 or 1990 . A site was cunsidered used if a goldeneye had nested in the box in 1989 or 1990 or both 
years. Data from each nest site were entered only once in the analysis w ensure independence of data.

\section{Measures of Female Quality}

I used the estimated weight of female goldeneyes prior to egg-liỵng as an index of female quality. Estimated prelaying weight was calculated by determining the weight of a female at the initiation of incubation and adding to this value $22 \mathrm{~g}$ for each egg in the clutch to correct for weight loss due to egg formation (see General Methods). Nest initiation dates of female common goldeneyes that were not determined by direct observation were determined by backdating from the hatching date. 


\section{Results}

\section{Lake use and activity hudgets:}

Between 2 May and 16 May, 19\%), I visited an average of 6.4 lakes per day. checking for the presence of breeding goldeneye pairs. This time period corresponded (o) the prelaying and egg-laying stages of reproduction for most pairs. Goldeneyes were observed more often on fishless wetlands (Table 1-1). When 1 restricted this analysis to experimental wetlands on which at least one breeding goldeneye pair was observed prior to incubation, breeding pairs were observed more often on tishless wetlands (Table 1-1).

Activity hudgets were recorded during the prelaying and egg-laying periods of each year. After I controlled for potential repeated observations of the same pair (by using mean values for the proportion of time spent in each activity for each pair; see Methods), I obtained a total of three female activity budgets from 1989 and 28 budgets from 1990). However, despite attempts to collect activity data on the few pairs foraging on wetlands containing tish, only two activity budgets were recorded. I excluded these data from all further analyses because there were too little to analyse. This left 29 activity budgets, all for pairs foraging on tishless wetlands. Date of observation and the time at which observations were recorded were uncorrelated with the proportion of time hens spent feeding, resting and preening, or in positive activities (all correlation coefficients $-(0.1<I<0.01$ : all $\underline{\text { P's }}>0.5)$. The number of pairs present on a wetland on which a hen was observed had a signiticant influence on the activities of that hen 
Table 1-1. Comparison of the number of breeding goldeneye pairs ohsenced prior wincuhaltion un all wetlands or experimental wetlands lacking or containing fish. Expurimental wetlands are thosc upon which a nest box had been erected.

\begin{tabular}{|c|c|c|c|c|}
\hline & \multicolumn{2}{|c|}{ Wellind Type: } & \multicolumn{2}{|c|}{ Experimentill Welland Typ.b } \\
\hline & Lackine Fish & Contuining Fish & Lacking Fish & Cinntainins Fish \\
\hline Pairs Observed & +0 & 7 & 20 & 5 \\
\hline Pairs Absent & 13 & .36 & $h$ & 25 \\
\hline
\end{tabular}

- $\left(\mathrm{X}^{2}=33.3,1\right.$ d.f., $\left.\mathrm{P}<0.001\right)$

$b\left(X^{2}=20.5,1\right.$ d.f., $\left.\mathrm{P}<0.001\right)$ 
(Table 1-2). Nearly $60 \%$ of the observations of hens on clustered wetlands were made while at least one other pair was present, whereas other pairs were present in only $33 \%$ of the cases on isolated wetlands. Lake isolation should not create inherent differences in invertebrate thundance between fishless wetlands (because aquatic invertebrates disperse well), so I pooled data from isolated and clustered wetlands and examined the effects of competition from other pairs on the activities of breeding hens. As predicted, female goldeneyes on svetlands where no other pairs were present spent less time foraging but more time resting and in positive activities than temales on wetlands where one or more other pairs wers present (Table 1-2).

\section{Nest site selection:}

The number of nest boxes available annually varied from 47 to 68 boxes beiween 1987 and 1990 (Table 1-3). Seventy-eight common goldeneye nests were found. as well as 23 hooded merganser nests, four common merganser (Mergus merganser) nests, and two wood duck (Aix sponsa) nests.

Eecause the presence of fish in a wetland strongly influenced use of the wetland hy goldeneyes during : - lying and egg-layirig periods, it may also affect nest site selection. Joldeneyes used nest boxes on fïshless wetlands more often than boxes located on wetlands containing fish (Table 1-4). However, this result may have been affected by other differences between these wetlands. Fishless wetlands were more acidic and were smaller than wetlands containing tïsh (Table 1-5). As well, distances from fishless wetlands to the next discrete water body or the next wetland were shorter 
Table 1-2. Comparisons of the proportions of time spent foraging. resting. or in combined positive activities by hens observed on wetlands with no other pairs present $(\underline{\mathbf{N}}=14)$ or with one or more other pairs present $(N=15)$ (MannWhitney $\underline{\underline{U}}$ Tests).

No other pairs One or more other pairs

Activity

Mean (SE)

Mean (SE)

$\underline{z}$

$\underline{P}$

Feeding

Resting

$0.38(0.04)$

$0.46(0.02)$

$-1.8$

0.117

Positive

$0.27(0.08)$

$0.06(0.03)$

$-2.6$

0.11

$$
0.65(0.05)
$$

$0.52(0.03)$

$-2.3$

(1.112 
Table 1.3. Annual availability and use of nest boxes by goldeneyes and other species in the study area.

\begin{tabular}{lllllll}
\hline & Available & Common & Hooded & Common & Wood & \\
Year & Nest Boxes & Goldeneyc & Merganser & Merganser & Duck & Unused \\
\hline 1987 & 47 & 19 & 3 & 1 & 0 & 24 \\
1948 & 48 & 19 & 6 & 0 & 11 & 23 \\
1989 & 68 & 18 & 6 & 1 & 0 & 43 \\
1990 & 61 & 22 & 8 & 2 & 2 & 27 \\
& & & & & & \\
Mean & 56 & $35.7 \%$ & $10.2 \%$ & $1.7 \%$ & $0.8 \%$ & $51.6 \%$ \\
\hline
\end{tabular}


Table 1-4. Comparison of goldeneye box occupancy in 1989 or 1990) on wetlands lacking or containing fish $\left(\underline{X}^{2}=6.6,1\right.$ d.f., $P=(0.01)$.

Wetland Type

Box Fate

Occupied

Unoccupied
Lackine Fish

18

11
Containing Fish

9

22 
Table 1-5. Habitat and nest box characteristics (mean [SE]) of experimental wetlands lacking ( $\underline{N}=30)$ or containing fish $(\underline{N}=31$ ) (Mann-Whitney $\underline{U}$ tests).

\begin{tabular}{lllll}
\hline & Wetlands & Wetlands & & \\
& Lacking & Containing & & \\
Variable & Fish & Fish & $\underline{\mathrm{Z}}$ & \\
& & & & \\
\hline BOXHT (m) & $5.0(0.3)$ & $5.6(0.3)$ & -0.6 & 0.56 \\
DISTH20 (m) & $4.9(4.7)$ & $3.4(2.6)$ & -1.0 & 0.29 \\
CBH (m) & $100(30)$ & $100(30)$ & -0.03 & 0.98 \\
AREA (ha) & $4.7(4.6)$ & $7.8(6.3)$ & -2.8 & 0.006 \\
NEARLK (m) & $182(147)$ & $284(219)$ & -2.6 & 0.01 \\
NEARBX (m) & $737(1066)$ & $849(705)$ & -2.4 & 0.02 \\
NLKIK & $4.0(1.9)$ & $3.3(1.7)$ & -1.6 & 0.10 \\
pH & $5.2(0.9)$ & $6.1(0.7)$ & -4.7 & $<0.001$ \\
& & & & \\
\hline
\end{tabular}


than the corresponding distances for wetlands with fish (Table 1-5).

To determine whether characteristics other than the presence or absence of lish affected nest site selection by common goldeneyes, I examined the characteristics of occupied and unoccupied boxes within wetlands containing fish and wetlands lacking fish. Occupied and unoccupied nest boxes did not differ in most meisured characteristics of the habitat surrounding the site (Table 1-6). The only significim! differences occurred for boxes erected on tishless wetlands. where boxes were accupied on wetlands of relatively higher $\mathrm{pH}$ and with fewer other water bodies within a $1 \mathrm{~km}$ radius (Table 1-6). I performed discriminant function analysis (DFA) within tishless wetlands and wetlands with fish to characterize the habitat surrounding used and unused nest boxes. The discriminant function derived from the analysis of fishless wetlands was significant $\left(\underline{X}^{2}=7.8,2\right.$ d.f., $\underline{P}=0.02$; Table 1-7), whereiss the function derived for wetlands containing fish was not significant $\left(\underline{X}^{2}=4.2 .4\right.$ d.f., $\underline{P}=0.31$ : Table 1-7). On fishless wetlands, the number of water bodies within a $1 \mathrm{~km}$ ridlius of the breeding wetland and tree size contributed significantly to the discrimination of occupied and unoccupied boxes (Tahle 1-7). Goldeneyes nesting on fishless wetlinds selected sites which had fewer wetlands nearby and nest boxes erected on larger trees. None of the measured variables contributed significantly to discrimination of sccupied and unoccupied boxes on wetlands containing tish (Table 1-7), indicating that goldeneye site choice on wetlands containing fish was not significantly influenced by any of the measured factors. 
Table 1-6. Hiabitat characteristicx (mean [SE]) of occupied and unoccupied nest boxes on wellands lacking or containing fish (Mann. Whitncy $\underline{U}$ Tests).

\begin{tabular}{|c|c|c|c|c|c|c|c|c|}
\hline \multirow[b]{2}{*}{ Variable } & \multicolumn{4}{|c|}{ Lackine Fish } & \multicolumn{4}{|c|}{ Containiny Fish } \\
\hline & $\begin{array}{l}\text { Used } \\
(\underline{N}=18)\end{array}$ & $\begin{array}{l}\text { Unused } \\
(\underline{N}=11)\end{array}$ & $\mathbf{Z}$ & $\mathbf{P}$ & $\begin{array}{c}\text { Used } \\
(\underline{N}=9)\end{array}$ & $\begin{array}{l}\text { Unused } \\
(\underline{N}=22)\end{array}$ & $\mathbf{Z}$ & P \\
\hline BOXHT (m) & $5.1)(11.2)$ & $4.9(11.2)$ & -11.25 & 0.80 & $5.4(0.3)$ & $5.6(0.3)$ & $-(1) .09$ & 0.92 \\
\hline DISTH?) (m) & $4.1(0.9)$ & $5 .+(1.8)$ & $-(1) .112$ & 0.98 & $2.6(1.8)$ & $3.8(1) .6)$ & -1.17 & 0.24 \\
\hline $\mathrm{CBH}(\mathrm{cm})$ & $1113 \quad(7)$ & y) (8) & -0.20 & 0.84 & 91 (4) & $106(7)$ & -1.45 & 0.14 \\
\hline NLKIK & $3.3(0.5)$ & $5.2(0.4)$ & .2 .41 & 0.02 & $2.9(0.8)$ & $3.6(0.4)$ & $-(1) .92$ & 0.35 \\
\hline ply & $5.4(0.2)$ & $4.8(0.2)$ & .2 .27 & 0.02 & $6.0(0.2)$ & $6.2(0.2)$ & $-(1.47$ & 0.64 \\
\hline AREA (hat) & $5.1)(1.3)$ & $5.4(1.0)$ & -1.17 & 0.24 & $7.3(1.1)$ & $8.2(1.5)$ & -0.63 & 0.53 \\
\hline NEARLK (m) & $2(16(38)$ & $157(44)$ & $-(1) .89$ & 0.37 & $309(113)$ & $281(41)$ & .0 .07 & 0.94 \\
\hline $\operatorname{NEARBX}(\mathrm{m})$ & $683(187)$ & t48 (194) & -1.07 & 0.29 & $822(212)$ & $833(152)$ & -0.05 & 0.96 \\
\hline
\end{tabular}


Table 1-7. Summary of the stepwise discriminant function analysis performed on nest box characteristics of boxes used and unused by common goldeneyes in 1984) or 1990.

Correlation between canonical function and variable

Variable

Lacking Fish

Containing Fish

NLK1K

$0.884^{1}$

0.387

NEARBX

$-0.538$

$-(0.3(k)$

pH

$-0.350$

0.211

AREA

0.197

$-(0.135$

$\mathrm{CBH}$

$-\left(10.129^{1}\right.$

0.5111

NEARLK

0.125

$-11.526$

BOXHT

$-0.112$

(1).182

DISTH20

0.039

0.316

Group Centroicis

Used

$-0.445$

$-(0.721$

Unused

0.729

0.275

' $P<0.05$, otherwise $P>0.05$, as determined by Wilks' lambda criterion 
I also tested whether goldeneyes preferred to nest in boxes used in the previous year over boxes that had been previously unused. For nest boxes erected on wetlands containing or lacking fish, goldeneyes nested in recently occupied boxes signiticantly more often than in previously unused nest boxes (Table 1-8).

\section{Effects of Female Quality}

I estimated prelaying weight for 24 female common goldeneyes that nested in 1989 or 1990 . Heavier females initiated nests significantly earlier than light females (r $=-0.55, \underline{N}=24, \underline{P}=0.005)$. I tested whether a relationship existed between female mass prior to laying and habitat quality by performing an ANCOVA with nest initiation date as a covariate. Contrary to my prediction, there were no significant differences between prelaying masses of females nesting on wetlands of different quality (Table 1 . 9). 
Table 1-8. Comparisons of goldeneye box occupancy in year $j$ in relition to occupalncy of the box in year $j-1$ based on data collected between 1987 and $19 \%($ ).

\begin{tabular}{lllll}
\hline & \multicolumn{2}{c}{ Wetlands Containing Fish" } & \multicolumn{2}{c}{ Wetliands Lacking Fish ${ }^{\circ}$} \\
Year $j$ & Occupied & Unoccupied & Occupied & Uncccupied \\
\hline Occupied & 11 & 4 & 22 & 10 \\
Unoccupied & 13 & 42 & 17 & 21 \\
\hline
\end{tabular}

-Comparison A: $\mathrm{X}^{2}=8.55,1$ d.f., $\underline{\mathrm{P}}=0.004$

'Comparison B: $X^{2}=4.06,1$ d.f., $P<0.04$ 
Table 1-9. Comparison of mean (SE) estimated prelaying mass of female goldeneyes nesting on four different types of habitats (ANCOVA, $E=0.09$, df $=3,20, P=$ 0.96; covariate nest initiation date).

Wetland type

Sample Size

6

5

5

8

Prelaying Mass

869 (25)

885 (16)

Clustered, Containing Fish

875 (17)

Clustered, Fishless 


\section{Discussion}

Both the presence of fish in wetlands and the proximity of a nest site (1) other water bodies influenced wetland use, female activity and nest site selection of breeding common goldeneyes. Female goldeneyes spent most of their time feeding and resting prior to incubation. Fishless wetlands were preferred as forigging sites, and. contrany 111 my prediction, fishless wetlands that had fewer nearby witter bodies were used more often as nesting sites. Goldeneyes also preferred to nest in hoxes crecupied in the previous year. Although tish presence and lake isolation affected nest site selection. there was $n 0$ evidence that female goldeneyes in the best condition prior to laying acquired nest sites on better quality wetlands.

Breeding females of many species of waterfowl feed heilvily on acpuatic invertebrates during the prelaying and egg-laying stages of reproduction to alcquire protein necessary for egg formation (e.g. Drobney 1980, Krapu 1981, Ankney and Afton 1988). Goldeneyes also feed primarily on invertebrates during hrood-rearing (Erikssin 1976). Eriksson (1983) found a negative correlation between the presence of fish in Swedish lakes and the use of those lakes by breeding goldeneyes and their young. Goldeneyes avoid lakes with large fish populations apparently beciluse these lakes have less abundant invertebrate prey (Eriksson 1983, Bendell and McNicol 1987a), and because fish compete with goldeneyes for these resources (Eriksson 1979h, Eadie and Keast 1982). In support of earlier studies, breeding goldeneyes at Wanapitei used small, fishless wetlands almost exclusively during the prelaying and egg-liying stiges, regardless of where their nest site was located. This resulted in certain wetlands being 
used as foraging sites by several pairs concurrently, leading to intraspecific aggression and competition for resources on these sites. When two or more goldeneye pairs were present on a wetland, hens spent less time in activities useful for egg tormation, suggesting that exclusive use of a wetland by one pair benefits the breeding hens in this area most.

During prelaying and egg-laying, female waterfowl spend most of their time feeding, and over three quarters of their time in positive activities (e.g. Afton 1979, Titman 1981, Savard 1988). Activites of female goldeneyes at Wanapitei prior to incubation are consistent with these earlier studies. Moreover, my prediction that female goldeneyes using wetlands where no other pairs were present (i.e. undisturbed females) would spend more time in positive activities than females sharing wetlands with conspecifics (i.e. disturbed females) was supported. Undisturbed females spent significantly more time resting and less time feeding than disturbed females. A plausible explanation for this pattern is that undisturbed females do not experience reduced foraging efficiency because of repeated harassment from conspecifics. Similarly, since undisturbed females can spend more time resting, their energy expenditures will be less, so they will not have to forage as long to replace energy used when feeding or avoiding competitors. In support of this explanation, I regularly observed escape tlight or diving behaviour by female goldeneyes sharing wetlands with conspecifics. As well, disturbed temales were usually alert after surfacing from a feeding dive, whereas undisturbed lemales usually surfaced and immediately began preening. 
The amount of time female goldeneyes allocated to positive activities maly have also been affected by the quality of their mates. Defence of a territury by the male provides the female with an undisturbed feeding area at a time of greit energy demilnd (Savard 1984). Females that had exclusive use of a wetland mily have heen matted (t) higher quality males that were $m r$ successful at preventing other pairs from using the wetland. Unfortunately I could not measure male quality directly to test this hypothesis. but indirect measures (e.g. response to simulated predators) suggest that males sharing wetlands with conspecifics may have been lower quality (M. Mall'ry and R. Walton. unpubl.). If female goldeneyes mated to higher quality males accuire sufficient reproductive reserves with a relatively lower cost than other females, then male quality may have a more significant impact of temale goldeneye reproductive success than previously suggested (Dow and Fredga 1985).

The presence of fish in wetlands appeared to have a significant influence (III wetland use prior to incubation, and it also affected the selection of nest sites by breeding female goldeneyes. As predicted, hens used nest boxis erected on fishless wetlands more often than boxes on wetlands containing fish. Female goldeneyes may benefit by nesting close to high quality wetlands because relatively less energy may be used travelling to feeding sites on incubation recesses (Ringelman et al. 1982, Hohman 1986b), and because ducklings would not have to travel tar to good feeding sites. If the presence or absence of tish in a wetland is a good index of available invertebrate food resources, then my results are in contrast to previous studies (Eriksson $1978,197 \%_{\mathrm{il}}$ ) that found tood availability had little influence on nest site selection by common 
goldeneyes in Sweden. However, more female goldeneyes at Wanapitei nested in boxes on wetlands containing fish than would have been expected based on wetland use prior to incubation. This was particularly surprising considering that many boxes on high quality, fishless wetlands remained unoccupied each year. Clearly most females ean determine which wetlands are high quality prior to egg-laying, thus it is unclear why many of these same females do not appear to use this information when acquiring nest sites.

Within fishless wetlands, those that had relatively tew nearby water bodies were prefer ied by goldeneyes over clustered wetlands. This was unexpected, since goldeneye duckling survival is lower when broods have to move further from a nesting to broodrearing wetland (Eriksson 197\%a). However, the difference in travelling distances from isolated or clustered wetlands to brood-rearing sites may not have a significant effect on duckling survival at Wan:ipitei (M. Wayland, unpubl.). If female goldeneyes assess the chances of duckling survival as roughly equivalent for most wetlands at Wanapitei, they may choose more isolated sites to minimize the costs associated with nest-site competition (Semel et al. 1988). While goldeneye choice of fishless wetlands as nesting sites was affected by lake isolation, goldeneye use of wetlands containing fish could not be characterized based on any of the measured variables. Goldeneye selection of these sites may be based on site characteristics not measured in this study. Alternatively, since these sites are low quality (based on food supplies), goldeneyes acquiring these nest sites may have been outcompeted for high quality sites on fishless lakes and may have chosen the closest cavity to attempt nesting. 
In addition to the presence of fish in wetlands, goldeneyce sest site selection wals affected by previous box occupancy. Commun goldeneyes prospect for nest sites in the summer prior to a nesting attempt, a beliaviour that has likely evolved in response (1) the limited availability of nest holes (Eadie and Gauthier 1985). Since many tomale goldeneyes prospect while other incubating females are still on their nests, prospecting females can gain information on the suitability of a nest site by determining the suicess of these occupants. If female goldeneyes use information alcquired from prospecting in the previous season, they should choose previously successful sites (Eadie and (jatulhier 1985). Dow and Fredga (1985) showed that female common goldeneyes preferred in nest in boxes recently occupied by conspecifics. and that this resulted in earlier mest initiations, larger clutches, and la.rger broods. My results were generally consislcht with these studies, in that common goldeneye hens used boxes occupied in the previous yeill more often than previously unused boxes. However, I lacked sufficient dalta (o alddress the questions of choice based on prior success and reproductive success in relation 11 prinr occupancy. The behaviour of choosing previously occupied hoxes maly explatin why goldeneyes used relatively more boxes on wetlands with fish than expected. Honded mergansers and common mergansers are piscivorous waterfowl and therefore maty prefer nest sites on wetlands containing tish. If temale goldeneyes choose previously successful nest sites used by any cavity-nesting waterfowl species, then sites on wetlanci: with fish may be considered suitable.

Despite the fact that certain types of wetlands were prefierred as foraging and nesting sites, there was no relationship between female quality and habitat quality (i.c. 
the best quality females did not acquire the best wetlands). This result can be interpreted in several ways. First, hreeding habitat quality may have a minimal effect on reproductive output and success at Wanapitei, so the highest quality temales may not risk potential injury by competing intensively for these sites. Second, measures of breeding site quality based only on lake isolation and fish presence may not reflect the true quality of the site. Both of these hypotheses are unlikely to be true, because fish presence and the degree of lake isolation both have significant impacts on goldeneye reproductive effort (Chapter 2). Finally, using female mass as the only index of female quality may not consider other important aspects of competitive ability (e.g. experience); thus competitively superior females may have acquired the higher quality sites.

In summary, breeding common goldeneyes used wetlands with the most abundant food resources during the prelaying and egg-laying periods, and generally preferred nest boxes erected on these wetlands as nesting sites. However, relatively more goldeneyes nested on poor quality wetlands than was expected, even though high quality sites remained available. As well, goldeneyes in the best breeding condition appeared not to acquire nest sites on the highest quality wetlands. Common goldeneyes can apparently assess wetland quality by the p. sence or absence of fish but do not use this intormation as the only basis for nest site selection. 


\section{CHAPTER TWO}

Effects of habitat quality and fomale quality on common goldeneye reproductive efforn 


\section{Introduction}

Parental investment theory predicts that females should invest in offispring in a manner that maximizes their lifetime reproductive success (Trivers 1972). For waterfowl, a large component of this investment is the amount of energy and resources used in producing a clutch (hereafter termed reproductive effort [RE]). One constraint on RE is the physical and energetic stress the breeding cycle produces on females (e.g. Ricklefs 1974), which may cause a trade-off between RE and the probability of surviving to breed again (Charnov and Krebs 1974). A second constraint on RE is that most female waterfowl have a finite amount of energy available for reproduction upon arrival at the breeding site. Hence, females should partition their energy reserves in a way that maximizes the number of offispring that will reach independence (Smith and Fretwell 1974, Brockelman 1975). If the food supply at hatching is likely to be good, females could produce more surviving oftspring by laying a large clutch of small eggs, because smaller ducklings would be able to acquire enough energy to survive. If poor conditions are expected, greater female success may be achieved by producing a smaller clutch of larger eggs, since greater energy reserves for individual offspring may allow them to survive longer until the food supply improves (Smith and Fretwell 1974).

The effects of breeding stress on lifetime reproductive success have been documented for some birds, where females producing larger clutches early in their breeding history do not live as long (e.g. Wooller and Coulson 1977, Ainley and DeMaster 1980, Dow and Fredga 1984). In any single breeding season, many 
proximate factors can also influence the annual RE (or clutch mass) of an individuall.

Causes of annual variation in RE have been intensively examined in watterfiowl beciluse these birds produce large clutches of relatively large, energy-dense eggs (King 1973. Rahn et al. 1975). While many of these factors are interdependent, they can be broadly grouped under three headings: effects of female quality. effects of hreeding habitat quality, and climatic effects. Clutch mass is the product of clutch size and average egg mass, so factors that affect either of these variables influence RE. First. females with large nutrient reserves prior to laying (i.e. body condition; Ankney and MacInnes 1978, Krapu 1981, Drobney 1982, Hohman 1986a. Hepp et al. 1987. Ankney and Afton 1988); that are dominant and pair earlier in winter (Hepp 19\$4. Rohwer and Andersson 1988); that are older or have more breeding experience (Krapu and Doty 1979, Bailey and Milne 1982, Dow and Fredga 1984); that are genetically superior (reviewed in Hailman 1986, Boag and van Noordwijk 1987): and/or that nest earlier (reviewed in Klomp 1970, Johnsgard 1973, Toft et al. 1984) tend to lay larger clutches. Second, females nesting in high quality habitat with abundant, protein-rict: ford cither during egg-laying (e.g. Lack 1967, Eldridge and Krapu 1988) or during browd-rearing (Danell and Sjoberg 1977) and with a lower risk of predation (Korschgen 1977, Perrins 1977) tend to lay larger clutches. Third, clutch size may be reduced by adverse weather conditions (e.g. Toft et al. 1984). While the studies mentioned above have demonstrated effects on clutch size, these and other studies have also shown similar effects on egg size (mass) (see Leblanc 1989). Thus female waterfowl must respond to) a myriad of proximate intluences in producing a clutch in any given year. 
In this chapter, I focus on several proximate factors affecting reproductive effort of female common goldeneyes. Specifically, I examined the effects of female quality and habitat quality on clutch mass of goldeneyes nesting in inan-made nest boxes adjacent to small, boreal lakes and wetlands. I used two indices of female quality (female experience and prelaying mass) and two indices of habitat quality (fish presence or absence and lake isolation). Heavier (i.e. in better condition) and more experienced females should be competitively superior (hence higher quality) than lighter, inexperienced females (e.g. Hepp 1984), so I predicted that higher quality goldeneyes would initiate nests earlier and lay clutches of greater mass than smaller females. Previous research has shown that fishless wetlands generally provide more abundant food resources (aquatic invertebrates) than wetlands with fish (Bellrose 1980, Eadie and Keast 1982, Bendell and McNicol 1987a). Similarly, several wetlands clustered together provide easy access to alternate feeding sites, thus less energy would be required to travel between these alternate feeding areas .. he nest site. Another consequence of clustered wetlands is that ducklings would not be subject to predation risk or physical stress for as long when travelling between wetlands (e.g. Ball et al. 1975. Eriksson 1979. Talent et al. 1983). Therefore. I predicted that female goldeneyes nesting or. fishless or clustered wetlands would lay clutches of greater mass than females nesting on isolated wetlands or those containing tish. Finally, waterfowl have a tinite amount of stored nutrient reserves upon arrival at the breeding grounds (e.g. Ankney and Afton 1988), so investment of resources to increase mean egg size in a clutch should result in smaller clutch sizes. Thus, I predicted that goldeneyes laying larger clutches should lay 
relatively smaller eggs, and I examined how dilferences in clutch size and egg size contributed to the observed patterns of clutch mass. 


\section{Methods}

\section{Measures of female quality}

The mass of a female duck before incubation is a good indicator of female quality (Hepp et al. 1987, Ankney and Afton 1988). I used estimated prelaying mass of each female as an index of temale quality (see General Methods).

Female waterfowl with previous breeding experience tend to lay larger clutches or larger eggs (e.g. Krapu and Doty 1979, Dow and Fredga 1984). Hence, I also used female experience as an index of female quality. A female was considered experienced if she was known to have bred previously in the study area, according to records from an ongoing Canadian Wildlite Service study.

\section{Measures of habitat quality}

I classified habitat quality using two criteria: presence of absence of tish (regardless of species composition), and proximity to neighbouring wetlands (see General Methods). Using these criteria I established four wetland categories: isolated containing tish, isolated lacking fish, clustered containing fish, clustered lackir g fish. I considered fishless and/or clustered wetlands to be relatively high quality breeding habitat, while wetlands containing tish and/or isolated were considered lower quality.

\section{Nest checks, parasitism, clutch size and eqg mass}

Goldeneyes move onto breeding sites shorily aiter ice breaks up on the lakes 
(Beilrose 1980), so I began nest box checks within seven dalys atter the ice wals olf the study lakes. Once nests were initiated, my subsequent nest visits (in approximatedy three day intervals) allowed me to determine when egg-laying was initiated. Datta on clutch sizes and nest initiation dates were collected in 1988, 1989) and (9)(T). The ditti for Wanapitei suggest that females lay one egg per day, a slightly higher rate than in other studies (Lumsden and Wenting 1976, Eriksson 1979a). Thus, for nests found after several eggs had been laid, I assumed a laying rate of one egg per day and calculated the date of nest initiation by backdating.

Common goldeneyes regularly parasitize the nests of conspecifics (Eadie et all. 1988), so I had to determine whether clutches included eggs of two or more females. I recognized parasitized clutches by four methods: 1) egg deposition rates exceeding one egg per day (Dow and Fredga 1984); 2) obvious differences in the appearance of eggs (usually colour) (Dow and Fredga 1984); 3) visual or electronically recorded observations of a non-resident female in the nest box during the laying of an egg; and 4) a total clutch size of greater than 10 eggs. I chose 10 eggs as the maximum clutch size for a single temale because this was the maximum size of goldene, clutches where parasitism was rare (Dow and Fredga 1984), and because all clutches that I concluded had been parasitized (based on other techniques) had a minimum of 11 eggs. Usually identification of parasitized clutches could be corroborated by at least two methods. I excluded clutches smaller than five eggs from all analyses, because these were never incubated and were considered "dump nests" (nests where eggs are deposited without any reasonable chance of being incubated), possibly resulting from several temales. 
Occasionally eggs disappeared during incubation, presumably the result of predation or ejection by the resident female. However, no eggs were ever added to a clutch after the resident female began incubation. Therefore, clutch size was defined as the maximum number of eggs found in a nest box between the initiation of nesting and the beginning of incubation.

I identified each egg by numbering eggs with a waterproof marker. I measured the length and width of each egg to the nearest $0.1 \mathrm{~mm}$ with calipers. A sample of goldeneye eggs was weighed to the nearest $0.5 \mathrm{~g}$ with a $100 \mathrm{~g}$ spring balance. I found egg mass was highly predictable from the length and width of an egg $(\underline{r}=0.92 . \underline{N}=$ 132, $\mathrm{P}<0.001)$. The equation for predicting egg mass was:

$$
M=0.000453(L)\left(W^{2}\right)+12.896,
$$

where $M$ is egg mass, $L$ is egg length, and $W$ is egg width. Clutch mass was the sum of the masses of each of the eggs in the clutch, and was calculated only for clutches where all eggs had been measured.

Some data were incomplete for certain clutches due to egg loss. Data from these nests were used where appropriate, resulting in different sample sizes for certain tests. Data were analyzed using a microcomputer version of the Statistical Package for the Social Sciences (Nie 1988). All means are reported \pm 1 SE. 


\section{Results}

Between 1988 and 1990, approximately 20\% of the goldeneye nests at Wallalpilei were parasitized intraspecifically. Unless otherwise stalted. all compuarisons below use only data for unparasitized nests; however, to demonstrate the effect of nest parrasilisin on the variables discussed below, I have included data from both unparasitizced allid all nests in some of the corresponding tables.

Clutch sizes and nest initiation dates were normally distributed in citch yeilr of the study (Kolmogorov-Smirnov tests, all P's > (0.05). The mean goldeneye clutch size was $8.3 \pm 0.2$ eggs $(\underline{N}=47)$. Goldeneyes laid similar-sized clutches in all three years of the study (ANOVA; $E=0.26, \underline{d f}=2.44, \underline{P}=0.77 ;$ Table 2-1). The mean nest initiation date was May $10 \pm 1.2$ days $(\underline{N}=47)$, and the means of g(uldeneye initialtion dates did not differ significantly between years (ANOVA; $\underline{E}=0.77, \underline{\text { di }}=2.44, \underline{P}=$ 0.47; Table 2-2). The average common goldeneye egg (including parasitic eggs:) weighed $65.1 \pm 0.2 \mathrm{~g}(\underline{\mathrm{N}}=403)$. Using data from 31 complete, unparasitized clutches, mean egg mass was $66.2 \pm 0.7 \mathrm{~g}$ and mean clutch mass wals $541.1 \pm 16.4 \mathrm{~g}$. Meill ceg mass and mean clutch mass did not differ between years $\left(t_{e g g}=0.05, P=0.52\right.$; $t_{\text {cluteh }}=0.25, \underline{P}=0.80$; Table 2-3). Since there were no significant differences between years for any of these variables, I pooled data on clutch size, nest initiation date, egg mass and clutch mass across years. 
Table 2-1. Mean clutch sizes for common goldeneyes in each year of observation.

\begin{tabular}{lcccccc}
\hline & & All nests & \multicolumn{4}{c}{ Unparasitized nests } \\
Year & Sample & Mean & SE & Sample & Mean & SE \\
& Size & & & Size & & \\
& & & & & & \\
1988 & 18 & 9.3 & 0.6 & 15 & 8.3 & 0.4 \\
1989 & 21 & 9.5 & 0.6 & 17 & 8.4 & 0.3 \\
1990 & 20 & 9.4 & 0.6 & 15 & 8.1 & 0.4 \\
\hline
\end{tabular}


Table 2-2. Mean Julian date of nest initiation for common goldeneyes in cilch year of observation.

\begin{tabular}{|c|c|c|c|c|c|c|}
\hline \multirow[b]{2}{*}{ Year } & \multicolumn{2}{|c|}{ All nests } & \multicolumn{4}{|c|}{ Unparasitized nessts } \\
\hline & $\begin{array}{l}\text { Sample } \\
\text { Size }\end{array}$ & Mean & SE & $\begin{array}{l}\text { Sumple } \\
\text { Size }\end{array}$ & Meinl & $\mathrm{SE}$ \\
\hline 1988 & 18 & 130.1 & 1.8 & 15 & 128.7 & 1.9 \\
\hline 1989 & 21 & 132.0 & 1.8 & 17 & 1.32 .5 & 2.1 \\
\hline 1990 & 20 & 129.3 & 2.1 & 15 & 1.31 .3 & 2.5 \\
\hline
\end{tabular}


Table 2-3. Mean egg mass (g) and mean clutch mass (g) for complete common goldeneye clutches in 1989 and 1990. Mean egg mass is the mean of the average egg mass for each complete clutch.

\begin{tabular}{lccccc}
\hline & & \multicolumn{2}{c}{ Eug Mass } & & \multicolumn{2}{c}{ Clutch Mass } \\
Year & Sample & Mean & SE & Mean & SE \\
& Size & & & & \\
\hline 1989 & 21 & 65.8 & 0.7 & 620.8 & 36.1 \\
1990 & 19 & 65.0 & 0.9 & 607.2 & 34.6 \\
\hline
\end{tabular}




\section{Clutch mass}

\section{Female quality}

My predictions concerning the effects of temale quality on clutch mass werte supported. Females nesting later in the season lajid clutches of less mass ( $\underline{r}=-(1.4 S . \underline{I}$ $=31, \underline{P}=0.006 ;$ Figure 2-1a). Heavier females initiated nests earlicr $(\underline{r}=-11.5 x . \underline{N}=$ 24, $\mathrm{P}=0.004$; Figure 2-1b), and heavier females laid clutches of greatter mass (I $=$ 0.65. $\underline{N}=23, \underline{P}=0.001:$ Figure 2-1c). However, temale goldeneyes with previous breeding experience were not heavier than inexperienced females and did not laty clutches of greater mass (Table 2-4).

\section{Habitat quality}

Nest initiation dates did not differ for female goldeneyes nesting on wellands differing in tish status or degree of isolation (Table 2-5). As shown previously (Chalpter One), estimated prelaying mass of breeding goldeneyes was similar for females nesting on each of the four wetland categories.

The prediction that goldeneye slutch m: $:$ would vary with habitill quallty wats supported (Table 2-5). The effects of nest initiation date were controlled for by performing an ANCOVA with initiation date as the covariate and lake isolation and fish status as main effects (Table 2-5). Only the presence of tish in a welland allected clutch mass $(E=5.6, \mathrm{df}=1,26, \underline{\mathrm{P}}=0.03)$; lake isolation had no significant eflect $\underline{\underline{E}}=$ $0.03, \mathrm{df}=1,26, \underline{\mathrm{P}}=0.86 ;$ ANCOVA, Table 2-5), and when lake isolituon was excluded from the ANCOVA, the variation explained by fish and initiation date remained at 
Figure 2-1. Relationships berween a) nest initiation date and clutch mass, b) nest initiation date and estimated prelaying mass of female goldeneyes, and c) estimated prelaying mass of female common goldeneyes and clutch mass. 

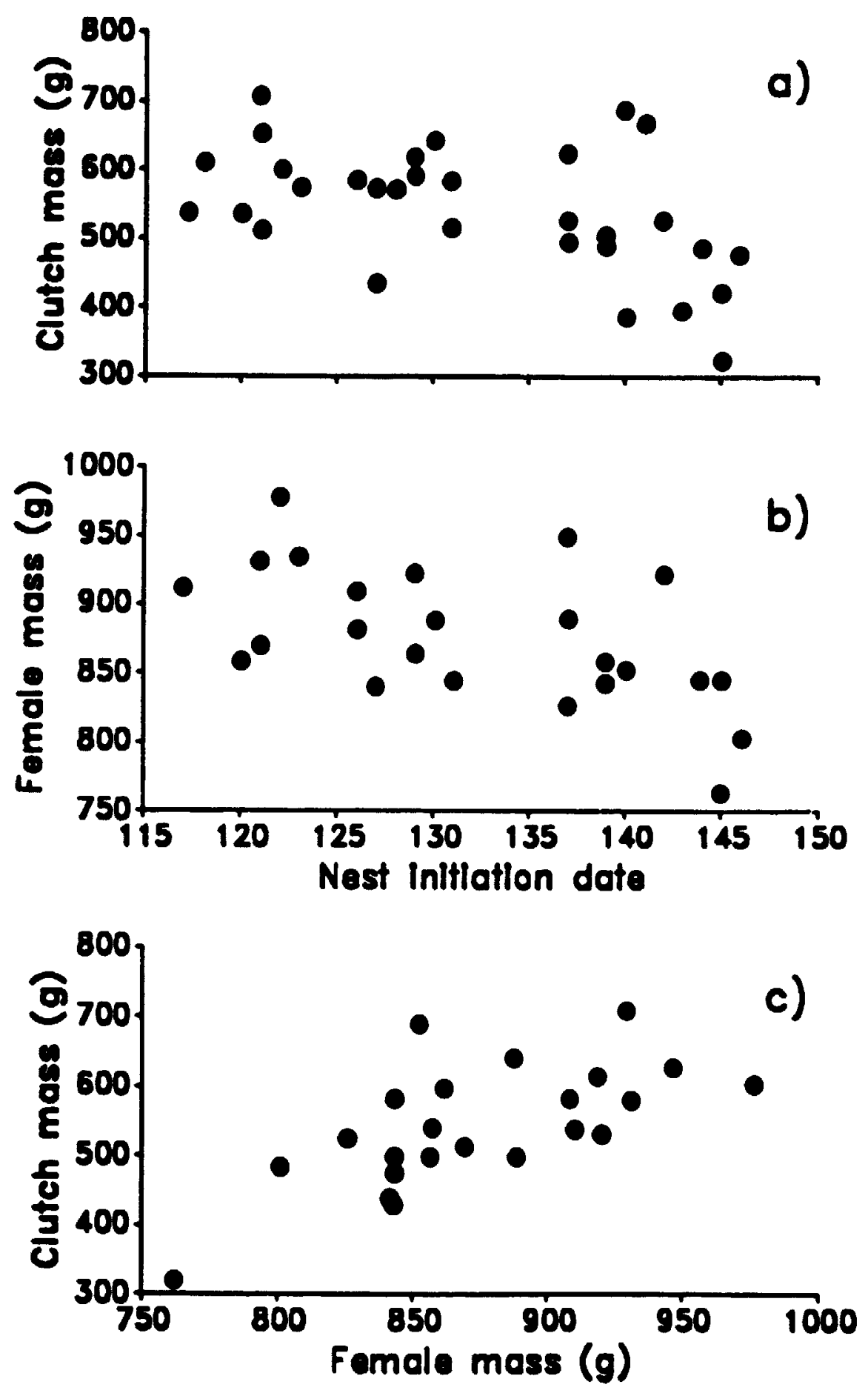
Table 2-4. Comparisons of breeding variahles of experienced and in'xperienced temale common goldeneyes at Wanapitci (Mann. Whitncy $U$ tests). Initiation dates are presented in Julian Jates. Egg mass, clutch size and prelaying female mass are in grams. Parasitized nests are cxcluded.

\begin{tabular}{|c|c|c|c|c|c|c|}
\hline \multirow[b]{2}{*}{ Variable } & \multicolumn{2}{|c|}{ Previous Breceders } & \multicolumn{2}{|c|}{ First-time Brecders } & \multirow[b]{2}{*}{$\mathbf{Z}$} & \multirow[b]{2}{*}{$\mathbf{P}$} \\
\hline & $\mathbf{N}$ & Mean (SE) & $\mathbf{N}$ & Mcan (SE) & & \\
\hline Initiation Date & 11 & $123.6(1.7)$ & 30 & $133.3(1.6)$ & -3.17 & 0.0012 \\
\hline Female Mass & 5 & $898 \quad(38)$ & 19 & $868 \quad(51)$ & -1.17 & 0.24 \\
\hline Clutch Size & 8 & $8.6(1) .5)$ & 24 & $8.1(0.3)$ & -0.94 & 0.35 \\
\hline Egg Mass & 7 & (x).2 (2.1) & 24 & $65.6(0.6)$ & -1.04 & 0.30 \\
\hline Clutch Mass & 7 & $5711.2(30.8)$ & 24 & $532.6(19.2)$ & $-(1) .80$ & 0.42 \\
\hline
\end{tabular}


Table 2-5. Comparison of mein $( \pm S E$ ) initiation date. clutch size. cyg matss and clutch mass of goldeneyes nesting in four types of habitats.

\begin{tabular}{|c|c|c|c|c|}
\hline Breeding Habitat & Initation Date (N) & Clutch site (N) & 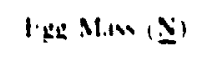 & $(\operatorname{lut}, \mathrm{N}) \ldots, \mathbf{N})$ \\
\hline Isolated, with Fish & $130.6 \pm 4.1(8)$ & $\because 9 \pm 0.4(8)$ & $(6,1) \pm 111(10)$ & $f(x) \| 1+:=11(1)$ \\
\hline 1solated, Fishless & $128.5 \pm 2.5(13)$ & $82 \pm 0.4(12)$ & $(m, 1) \pm 101-1$ & $59: \pm(21)$ \\
\hline Clustered, with Fish & $130.3 \pm 2.8(9)$ & $7.3 \pm 11+(7)$ & $(x) \pm 20(5)$ & $|x| \pm \ln _{0}(0)(5)$ \\
\hline Clustered. Fishless & $131.4 \pm 1.4(24)$ & $8.8 \pm 0.3(201)$ & $053 \pm 114(13)$ & $6024 \pm 277(13)$ \\
\hline Probability & $07 \times 1$ & $<(1)(n)\}^{2}$ & $0 \leq x^{1}$ & $\| 11^{2}$ \\
\hline
\end{tabular}

1Probathlity hased on one wily ANONA

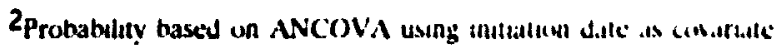


37\%. Female goldeneyes nesting on wetlands containing tish laid clutches of less mass than females nesting on fishless wetlands.

\section{Relationship between clutch size and equ size}

For all clutches, mean egg mass decreased with increasing clutch size $(\underline{r}=-() .39$. $\underline{N}=40, \underline{P}=0.01)$. However, this pattern disappeared when parasitized clutches were excluded from the analysis $(\underline{r}=-(0.19, \underline{\mathrm{N}}=31, \underline{\mathrm{P}}=0.30)$. Mean egg mass was lighter in larger, parasitized clutches than smaller, unparasitized clutches because eggs laid parasitically tended to be smaller $(\underline{X}=65.3 \pm 0.4 \mathrm{~g}, \underline{\mathrm{N}}=66)$ than eggs laid by host females $(\underline{X}=66.2 \pm 0.3 \mathrm{~g}, \underline{N}=222 ; \underline{t}=-1.93, \underline{P}=0.06)$. Thus. contrary to my prediction, goldeneyes that laid larger clutches did not lay smaller eggs. To determine how goldeneyes adjusted clutch mass in relation to temale or habitat quality. I examined the independent effects of female mass or experience and wetland quality on clutch size and egg size.

\section{Clutch size}

As predicted, early-nesting goldeneyes laid significantly larger clutches than latenesters ( $\underline{r}=-(0.44, \underline{N}=47, \underline{P}=0.0(1) 2$, excluding parasitized nests). Heavier temale goldeneyes initiated nests earlier (see above) and laid more eggs $(\underline{r}=0.63, \underline{\mathrm{I}}=2.3, \underline{\mathrm{P}}$ $=0 .(0) 1)$ than lighter females. However, temale goldeneyes that had previously bred in the study site did not lay more eggs than first-time breeders (Table 2-4).

I tested whether habitat quality intluenced goldeneye clutch size using the same 
procedure as outlined in the clutch mass analysis (ANCOVA). Excluding parassitized nests, the presence of fish in a wetland resulted in reduced clutch sizes for nesulng females $(E=6.5$, of $=1,44, \underline{P}=0.01$ : Table 2.5), while the effect of wetland isulation was not significant $(\underline{F}=1.2$, df $=1,44, \underline{P}=0.14)$.

\section{Egg mass}

Mean egg mass was unrelated to nest initiation date for unparasitized clutclees (r $=-0.19, \underline{N}=31, \underline{P}=0.30)$. Unlike the relationship between female quility and clutch mass or clutch size, heavier goldeneves did not lay larger eggs than lighter goldeneves (g $=0.11, \underline{N}=23, \underline{P}=0.62)$. As well. older female gotdeneyes with previous breeding experience did not lay heavier egges than first-time breeders (Tible $2-4$ ).

Nesting habitat quality had no significant effect on the size of eggs fermile goldeneyes produced. Mean egg mass did not differ for females nesting on wetlands of differing fish status or degree of isolation (Table 2-5). 


\section{Discussion}

Before discussing the effects of habitat quality and female quality on goldeneye reproductive effort, it is useful to review the relationship between clutch mass, clutch size and egg size. Clutch mas: is the product of clutch size and egg mass, and the clutch mass that a female can lay is limited by the amount of nutrients (especially lipids) she can store for reproduction (e.g. Ankney and Macinnes 1978, Ankney and Afton 1988). I predicted that females laying large clutches would produce smaller eggs, because energy (i.e. the amount of stored nutrient reserves) invested in larger eggs reduces the energy available to produce more eggs (Smith and Fretwell 1974 , Brockelman 1975). However, clutch size was unrelated to egg size in goldeneyes. a result consistent with studies on other waterfowl species (Rohwer 1988). Moreover. clutch size was correlated with both female and habitat quality, whereas egg mass was independent of these variables. Thus, variation in clutch mass arises from variation in clutch size, not egg mass.

In support of my predictions. both female quality and habitat quality affected goldeneye reproductive effort. Female goldeneyes of relatively low quality (hens that weighed less and nested later in the season) laid clutches of lower mass than did higher quality female goldeneyes. Lighter females probably retained smaller stored reproductive reserves, and thus had fewer resources available for clutch formation. Hepp et al. (1987) found that lower quality female wood ducks also laid clutches of less mass. Similarly, lighter temales usually lay smaller clutches than heavier females in most other North Americin watertowl species (e.g. Ankney and MacInnes 1978, Krapu 
1981, Drobney 1982, Hohman 1986, Ankney and Afton 1985). As well. Lwer quality. late-nesting female goldeneyes may have allocated fewer resources to egg production not only because they possessed smaller reproductive reserves, but because goldelliege ducklings hatched from late nests do not survive as well as early-hattched ducklings: (Dow and Fredga 1984).

My prediction that females nesting on high quality habitats would lity clutchess of greater mass was also supported. The presence of tish (which determines the amount of available food resources) in a wetland was correlated with the amount of resources female goldeneyes invested in a clutch. Female goldeneyes nesting un fishless metlinds may have allocated more resources to clutch production for iwo reatsoms. Pirst. duckling survival should be higher on wetlands containing abundant food resources (Danell and Sjoberg 1977), so females that laid more eggs in nest sites on these wetlands should produce more offspring that reach independence. Second, females nesting on these types of wetlands may acquire more resources tor clutch production at a reduced energetic cost (i.e. risk of physical deterioration), and thus commit a greater ammount (1) resources to their clutch (Lack 1967, Eldridge and Krapu 1988). In support of this contention, previous studies have demonstrated that the abundance of wetland ford resources can markedly affect clutch size in waterfowl (e.g. Lack 1967, Bengston 1971).

I expected that goldeneyes nesting on isolated wetlands would devote lewer resources to their clutch, because duckling survival is lower for broxds that hitve t1) travel further to brood-rearing sites (Ball et al. 1975, Eriksson 1979, Talent et al. 1983). Thus clutches laid on isolated wetlands should be less valuable. Contrary to this 
prediction, lake isolation did not affect significantly goldeneye clutch mass. However, recent evidence suggests that duckling survival at Wanapitei is independent of distances that broods move (M. Wayland, unpubl. data). Therefore, if duckling survival does not differ for nest sites located on either isolated or clustered wetlands, it is unlikely that female goldeneyes base invest!nent decisions on this habitat characteristic.

Reproductive effort of female goldeneyes nesting at Wanapitei was higher if temales were in better condition or if they acquired nest sites on fishless wetlands. Whether these investment decisions result in improved (or impaired) reproductive success depends on the level of investment provided by the temale during incubation. and the survival of broods reared on wetlands of different quality. Currently little is known about goldeneye duckling survival on wetlands differing in acidity and fish status. Hunter et al. (1986) demonstrated that black duck (Anas rubripes) ducklings reared on fishless wetlands grew taster than those reared on ponds containing fish. However. black duck (Rattner et al. 1987) and ring-necked duck (Aythya collaris) (McAuley and Longcore 1988) young reared on acidic wetlands do not survive or grow as well as ducklings reared on circumneutral ponds. Provided goldeneye duckling survival is not affected by potential direct toxic effects on acidic wetlands (Eriksson 1984), female goldeneyes laying clutches and rearing young on tishless wetlands at Wanapitei probably experience higher annual reproductive success than females nesting on isolated wetlands containing tish. 


\section{CHAPTER THREE}

Effects of habitat qualing and fomale yundity

on common goldencye reproductive behationtr 


\section{Introduction}

The energetic cost of reproduction for waterfowl is relatively large compared (o) most other hird groups (King 1973, Ricklefs 1974). Costs associated with incubiltion of clutches can have significant impacts on reproductive success (e.g. Korschgen 1977). The behaviour of incubating waterfowl reflects a compromise between the developmental requirements of the embryos and the metabolic requirements of the parent to ensure their own survival. Hence, investment by the parent to enhance embryonic development usually results in increased risk to the parent s own physical condition or future reproductive success.

Many large waterfowl (e.g. geese and swans) fast during incubation. spending nearly all of their time incubating the clutch. and relying almost entirely on stored nutrient reserves (primarily lipids) to meet their metabolic costs of selt-maintenance (Macinnes et al. 1974. Ankney and Macinnes i978, Cooper 1978. Raveling 1979. Aldrich and Raveling 1983). However, smaller waterfowl have a reduced capahility to store large endogenous reserves, and must rely joth on stored reserves remaining after egg-laying and on environmental food resources to meet their metabolic requirements (e.g. Afton 1979, 1981). Drobney 1980, 1982, Reinecke et al. 1982. Tome 1984, Noyes and Jarvis 1985, Hohman 1980. Ankney and Afton 1988). The amount of nutrient reserves retained by a temale alter clutch completion (i.e. temale condition) can influence her nest altentiveness schedule (Gatti 1983, Thompson and Raveling 1987). For example, renesting watertowl tend to have lower attentiveness, which has been attributed to reduced endogenous reserves upon nest inititation (Afton 1980). 
Moreover, because smaller waterfowl must acquire food during incubattion recesses while maintaining a suitable environment (temperiture, humidity) in the nest for the embrjos, the scheduling of ro esses (duration and frequency) mily he affected nol anly by the amount of remaining metabolic reserves, but also by weather conditions (c.t. Afton 1980, Cartar and Montgomerie 1987), the availability of food (i.e. habitat quality) (Drent and Daan 1980, Dijkstra et al. 1984, Hohman 1986b, Jones 1987, Lumsde'n unpubl.), and nest locati $\cdot n$ (Ringelman et al. 1982, Hohman 1986h).

Females of most North American watertowl species attain their highest anmual body mass just prior to nest initiation. lose mass during egg-laying and incubation. and reach their lowest annual mass at or shortly after hatching (Korschgen 1977. Ankney and Maclnnes 1978, Peterson and Ellarson 1979. Drobney 1981, Gatti 1983, I Iohminl 1986a, Lumsden unpubl.). The amount of mass lost during incubation may allso be affected by the location of the nest site and the availability of food resources. Becousc flight is energetically costly (Wooley and Owen 1978), female ducks nesting relativcly fiur from feeding wetlands will use more energy flying further on incubation recesses (Ringelman et al. 1982), and hence more mass may be lost. If a femile loses too much mass during incubation, she may abandon the clutch (e.g. Korschgen 1977, J(mes [487) or may die (e.g. Korshgen 1977, Ankney and MacInnes 1978).

In this chapter, I focus on proximate factoss affecting the incubation behaviowir of female common goldeneves. I examined the effects of female quality and habitit quaity on the nest attentivenes; and incubation weight loss patterns of fiemale common goldeneyes nesting in artiticial nest boxes erected on boreal wetlands. The common 
goldeneye is a medium-sized (female mass ranges between $550-900 \mathrm{~g}$. Lumsden unpubl.), cavity-nesting duck that attempts to nest only once annually (Zicus 199(0). Males vigorously defend a feeding territory for the female during prelaying and egglaying periods (which allows the female to store lipid reserves: Salard 1985), but usually abandon the female by the third week of incubation (Bellrose 1980. M. Niniary pers. obs.). Large stores of endogenous nutrient reserves allow temale waterfowl to rely less on senvironmental food resources during incubation and can reduce reproductive costs associated with absence from the nest (e.g. egg cooling. energy lost in flight). Thus. I predicted that females commencing incubation with large nutrient reserves (i.e. heavier) would lose relatively more mass through incubation but would exhibit higher nest attentiveness than lighter females.

Goldeneyes are primarily insectivorous, relying heavily on aquatic intertebrates for protein during the breeding cycle (Bellrose 1980. Bendell and MeNicol unpubl.. Lumsden unpubl.), and compete with tish tor invertebrate prey (Eriksson 1979h. Eadie and Keast 1982). Since both the availability of food resources and nest location can aliect watertou.l reproductive performance (see above), breeding wetlands can be classified into four types: isolated containing tish, isolated tishless, clustered containing fish, and clustered tishless. Because clustered fishless wetlands are high quality. preferred feeding sites (Chapter One) and temales nesting on these wetlands invest the gratatest resources in clutch production (Chapter Two), I hypothesized that female goldeneyes nesting on clustered, fishle:s wetlands would have the highest nest attentiveness. In Chapter One I demonstrated that there was no correlation between 
the quality of a female goldeneye and the quality of her nesting habitat. Thus. I predicted that females nesting on isolated wetlands containing fish would somplete incubation in relatively poorer condition than females nesting on cluslcred wetlands. and would take relatively few but long daily incubation recesses (a more efticicn! micuhallim strategy when food is further away' [Drent 197.3]). Conversely. I preduled th.tt temale goldeneyes atesting on clustered. fishless wetlands would complete incuhattun in! relatively good condition. and would take more frequent, shorter incuhatum recesses. I

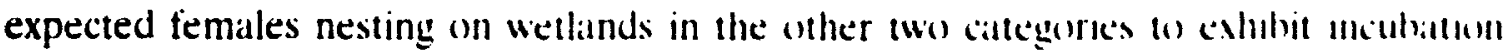
behaviours intermediate to these two extremes. Finally. it temake ropoudutase performance varies according to the quality of their nesting habitat. I eypected haltshug success of clutches laid on poor wetlands (isolated or containung tish) to be luwer. 


\section{Methuds}

\section{Incubation variables}

I examined three aspects of common goldeneye incubation: the amount of time incubating females spent on the nest each day (nest attentiveness), the mean length of each trip taken off the nest each day, and the mean number of trips taken off the nest each day. These variables correspond to the terms "incubation constancy", "recess duration" and "recess frequency" in Afton (1980) and Hohman (1986a). I defined day one of incubation as the day following the first entire night that the female spent on the nest.

\section{Incubation monitoring equipment}

Two types of monitoring systems were designed to measure goldeneye incubation rhythms and/or weight change (described in the General Methods). For nests discovered while eggs were still being laid. monitoring systems were installed on or shortly after the initiation of incubation. For all other nests. monitors were installed as soon as possible after an active nest was detected. Monitors recorded the number or trips females took off th. t. how long each of these trips lasted, and the mass of contents resting on the monitor.

\section{Calculations of changes in temale mass}

Female mass was calculated by subtracting the maximum recorded mass 
(excluding readings resulting from movement: sec General Mlethuds) if the temalc plus the eggs plus the nesting material when the temale was incubating trum the nevt maximum recorded mass of the eggs and nesting matterial alone (onl kemale mindoattun recesses). Using this procedure. the maximum recorded mass of ciah lemale was calculated tor each recorded day of incubation. The lowest of these salues (1.ce. Ha lowest daily maximum) was considered to be the minimum recorded mass athened during incubation. The result of dividing each daily maximum by the arerall minmum recorded mass was then expressed as a percentage of that minimum mass and lermed incubation mass. For example. if a temale goldeneye weighed orol) $g$ an the secollad day of incubation and the lowest recorded matss for that female during meubatton w.a (1) g. then on day ewo of incubation her ancubation mass wass $110 \%$ (lofe; abouc het minimum recorded mass during incubation).

\section{Measures of temale quality}

I used the estimated mass of temale common goldeneyes all the muallon of incubation as my index of female quality. Body mass is usually a good molex of the s/a of stored nutrient reserves in breeding wilterfowl (Hepp et il. 1987. Ankney and Allull 1988). I considered heavier females to be higher quality. Details of the mass estimation procedure are outlined in the General Methods.

\section{Measures of habitat quality}

I used two indices of habitat quality: presence or absence of fish, and degree of 
lake isolation. I considered clustered wetlands lacking fish to be high quallity. isolated wetlands containing fish to be low quality, and other wetlands to be intermediate in quality. Detailed descriptions of the study area, fish sampling procedures and determination of isolation are found in the General Methods.

\section{Hatching success}

I considered clutches where at least one egg hatched to be successful. I defined hatching success as the percentage of hatched eggs in successful clutches. 
Results

\section{Incubation rhythms}

Incubation rhythm data were collected from three goldenege nests in lust and 14 nests in 1990. For each individual incubation record. 1 excluded ditat trom the tisst five days of incubation becaluse incubation rhythms are usually mot establshled for ill females (Afton 1980). For example. a typical range of the daily ammumt of tume spe.ult off the nest during the first live days of incubation is 247 - 944 mun, while this riange is reduced to $134-301$ min hetween day six and day 301 of incubation. For each lemale. nest attentiveness and the mean length of recess breaks nere normally distrihuted (Kolmogorov-Smirnov tests, all $\underline{p}:>0.15$ ), but the number of recess breaths taken eath day was not normally distributed for most females.

I recorded incubation rhythms of five females nesting on isolitted wetlands containing tish, five rhythms of females nesting on isolated, fishless wedlands, and sa rhythms of females nesting on clustered, fishless wetlands. I recorded only pialtail ditti from one female nesting on a clustered wetland containing tish. so I excluded thus habitat category from the remaining analyses. To establish the patterns of nest attentiveness for females nesting on each habitat type, I pooled datat for temales mestung in each wetland type by incubation date (Figure 3-1). Goldeneyes nesting on isolated wetlands containing or lacking fish spent more time off the nest as incubatton proceeded (Figure 3-la,b), but females nesting on clustered. fishless wetlands spe'nt similar amounts of time off the nest during incubation (Figure 3-Jc). Both the number 
Figure 3.1. The relationship between the amount of time spent off the nest each day and incubation date for each habitat category.

Goldeneyes nesting on a) isolated wetlands containing fish ( $\mathrm{I}=$ $0.53, \mathbf{N}=25, \mathrm{P}<0.01$ ), and $\mathrm{b}$ ) isolated, fishless wetlands ( $\mathrm{I}=$ $0.71, N=25, P<0.001)$ spent increasingly more time off the nest as incubation proceeded, whereas goldeneyes on c) clustered fishless wetlands spent similar amounts of time off the nest throughout incubation $(I=0.11, N=25, P=0.61)$. Values for each day are represented by means and standard error bars. 


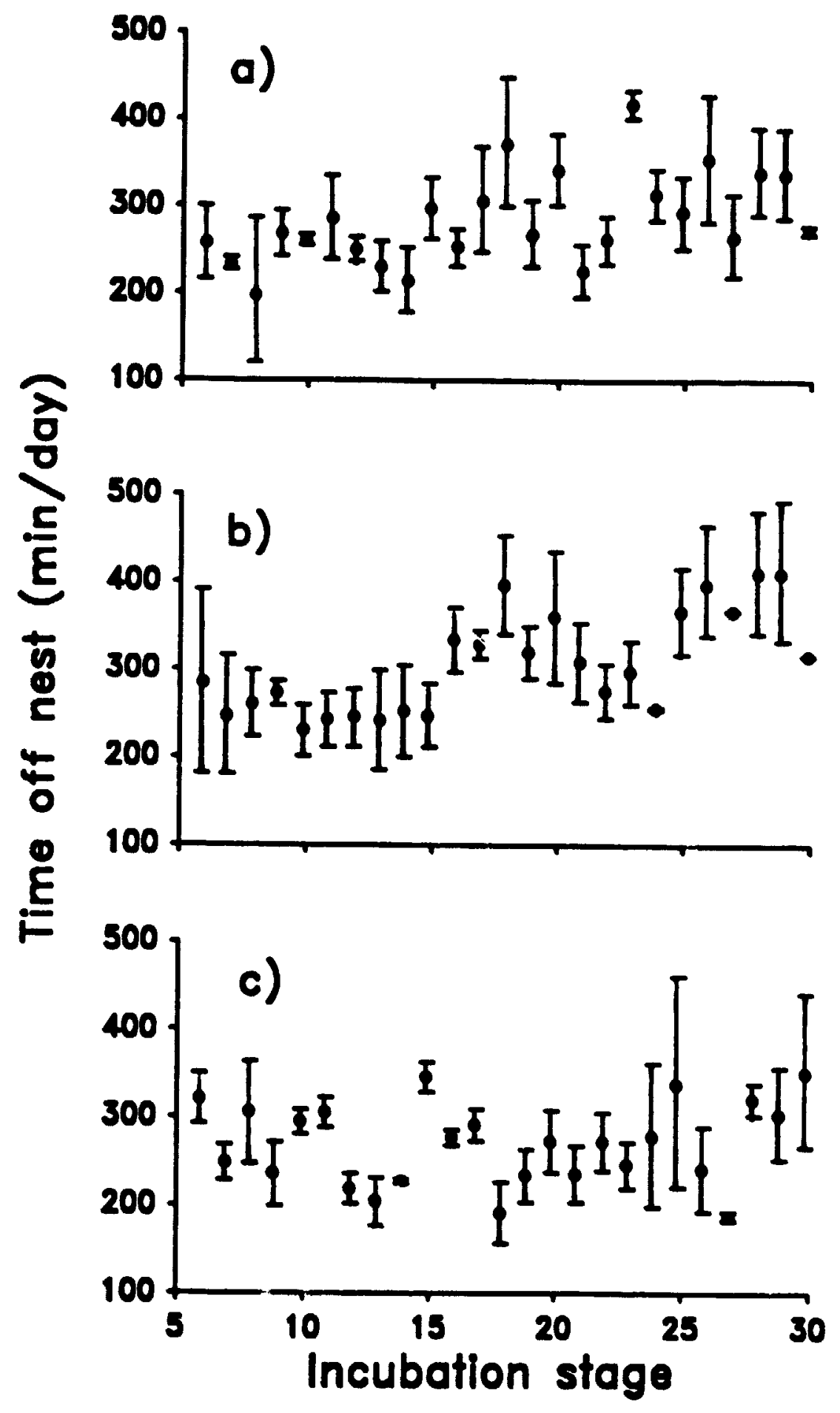


of daily incubation breaks and the mean duration of these breaks were uncorrelated with incubation stage for all habitat categories (all P's $>0.5$ ).

To examine the effects of habitat quality on incubation scheduling by female goldeneyes, I calculated means of each incubation rhythm variable (nest attentiveness. length of incubation breaks, and number of trips off the nest each daly) for the entire incubation period for each female. I then pooled female means of each of these variables by habitat caltegory. I tested whether the presence of tish in a wetland intluenced female incubation patterns by comparing means of each of the three incubation variables for females nesting on isolated wetlands containing tish with the corresponding means for temales using isolated wetlands lacking fish. There were no significant differences in the amount of time spent on the nest each day. the length of incubation recesses. or the number of incubation breaks taken per day between females nesting on either of these types of habitats (Mann-Whitney $\underline{U}$ tests. all $\underline{P}$ 's > 0.2: Table 3-1). For this reason. 1 pooled data for females nesting on isolated wetlands (regardless of tish presence or absence) and tested whether these temales scheduled incubation palterns differently from females nesting on clustered wetlands. Goldeneyes nesting on clustered wetlands spent more time on the nest each day (Mann-Whitney $\underline{\mathrm{U}}$ test. $\underline{Z}=$. 2.1, $\underline{P}=0.04$, Table 3-1) and tended to take shorter incubation breaks (Mann-Whitney $\underline{\mathrm{U}}$ test, $\underline{\mathrm{Z}}=-1.6, \underline{\mathrm{P}}=(0.10$; Table $3-1)$ than temales nesting on isolated wetlands. However, goldeneyes on clustered or isolated wetlands took similar numbers of trips off the nest each day during incubation (Mann-Whitney $\underline{\mathrm{U}}$ test, $\underline{Z}=-0.8, \underline{P}=0.41$ ). 
Table 3-1. Means $( \pm \mathrm{SE}$ ) of daily time spent on the nest. kength of recess breiths illd number of daily recess breaks tor temale goldeneyes nestm!g on hahitats ot differing quality.

\section{Habital Type}

Variable

Isolated With Fish Isolated Fishless

Clustered fishless

$$
(\underline{N}=5)
$$

$(\underline{N}=5)$

$(\underline{N}=(1)$

Time on nest (min/day)

$1161 \pm 14$

$1152 \pm 25$

$12(k) \pm 6$

Length of recess break ( $\mathrm{min}$ )

$127 \pm 17$

$119 \pm 9$

$93 \pm 5$

Nuinher of recess breaks

$2.5 \pm 0.2$

$2.9 \pm 11.2$

$2.9 \pm 11.2$ 
To examine the effects of female quality on nest attentiveness. 1 used the estimated mass of female goldeneyes at the start of incubation as my index of female quality. Nesting habitat quality had an influence on nest attentiveness, so to minimize this intluence on the analysis of effects of female quality. I calculated the difference between the mean nest attentiveness for each female and the mean attentiveness typical of females nesting in that habitat. Contrary to my prediction, female goldeneyes that were heavier at the initiation of incubation did not allocate more time each day to incubating their clutch $(\underline{r}=-0.40, \underline{N}=15, \underline{P}=0.14)$.

\section{Changes in female mass during incubation}

I collected data on changes in mass of incubating female goldeneyes from 12 females in 1990. Unlike the analyses on incubation rhythms. I used data collected from day one through day 30 of incubation. Using values of incubation mass for each female on each recorded day of incubation (Figure 3-2), 1 calculated an equation that describes the typical pattern of weight loss for incubating female goldeneyes. The equation is:

$$
I=0.01(D)^{2}-1.1(D)+122.2 .
$$

where $I$ is incubation mass and $D$ is the day of incubation. On the first day of incubation, a typical female goldeneye is approximately $21 \%$ heavier than the lowest mass it will reach during incubation. This value is consistent with measures of weight lust by incubating hens of other members of the tribe Mergini (reviewed in Gatti 1983).

I recorded masses of females nesting on three of the habitat types: seven records were collected from females nesting on isolated wetlands (four containing fish, 
Figure 3-2. The pattern of weight change for incubating common goldeneyes. 


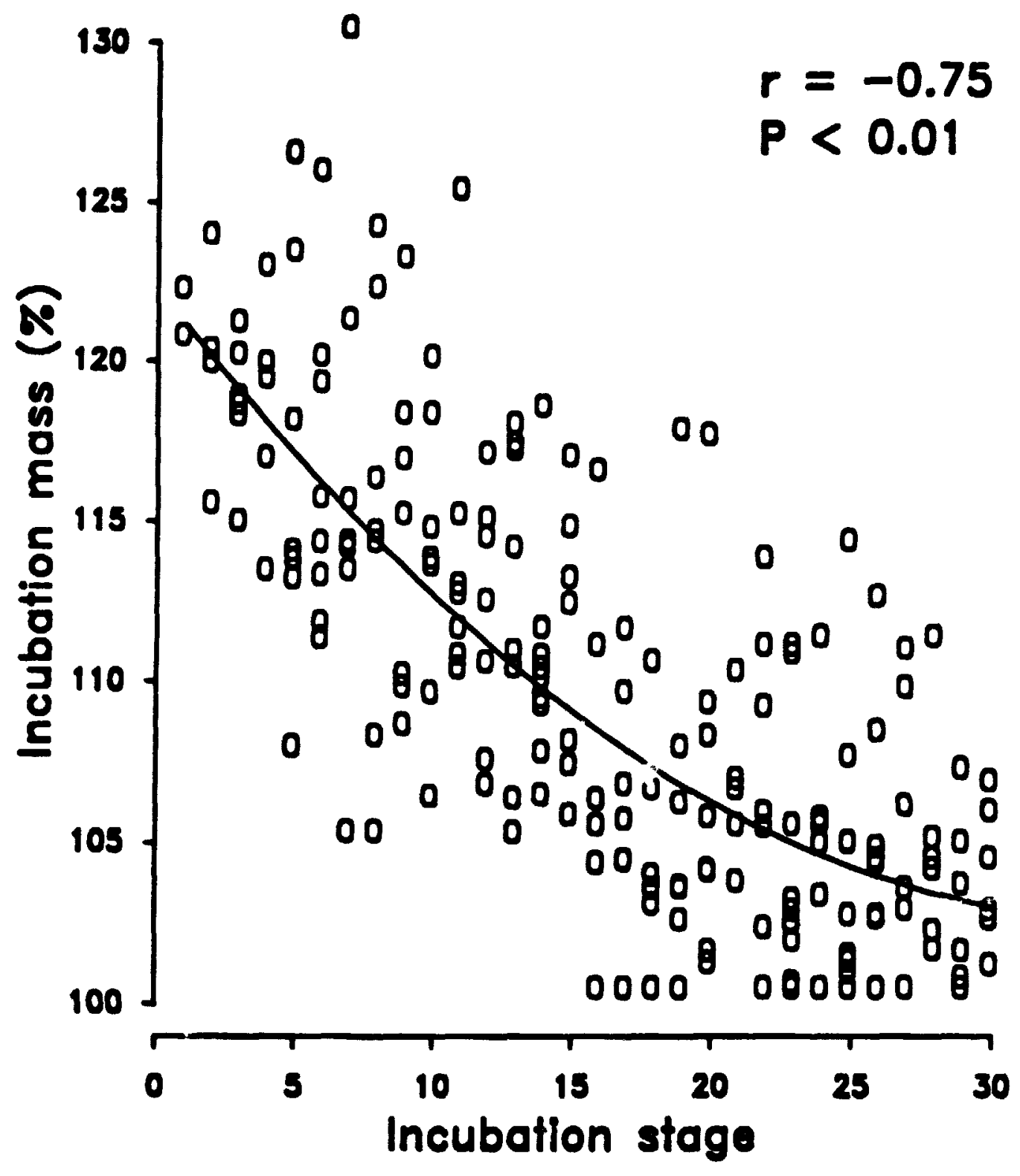


three lacking fish), while five records were collected from temalk's nesting (InI clustercel. fishless wetlands. Within eilch female, daily changes in temale mans were mormill! distributed (Kolmogorov-Smirnov tests, all P's > 0.05$)$. I calculitted the meall incubation mass tor each female during each week of incubation : trealting diı̣is 22 (1) 31) as one week). To analyse the effects of habitat type on weight change (if incubatting female goldeneyes, 1 pooled mean values of weekly incubattion mass for all femiales within each habitat category. I tested whether the presence of fish in a wetland influenced temale weight change patterns by comparing weckly mealls of incubation mass for females nesting on isolated wetlands containing fish and sollated wetlatlds lacking tish. The pattern of weight change did not differ hetween females nesting wa

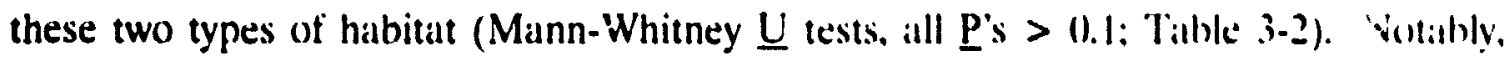
females nesting on isolated wetlands containing tish completed incubation in similat condition to females nesting on isolated, tishless wet!ands.

Fish presence did not affect the pattern of mass: loss for temales nesting on isolated wetlands, so I pooled data for all females nesting on isolated wetlands to test if the pattern of mass loss differed for females using isolated or clustered wetlands. The incubation mass of goldeneyes nesting on clustered wetlands did not differ from thatt al goldeneyes nesting on isolated wetlands during the fïst three weeks of incuballionl

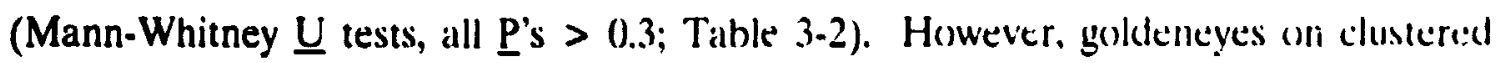
wetlands tended to complete incubation in relatively poorer phvisial condition ilan females using isolated wetlands (Mann-Whitney $\underline{U}$ test, $\underline{P}=0.07$; Table 3-2). 

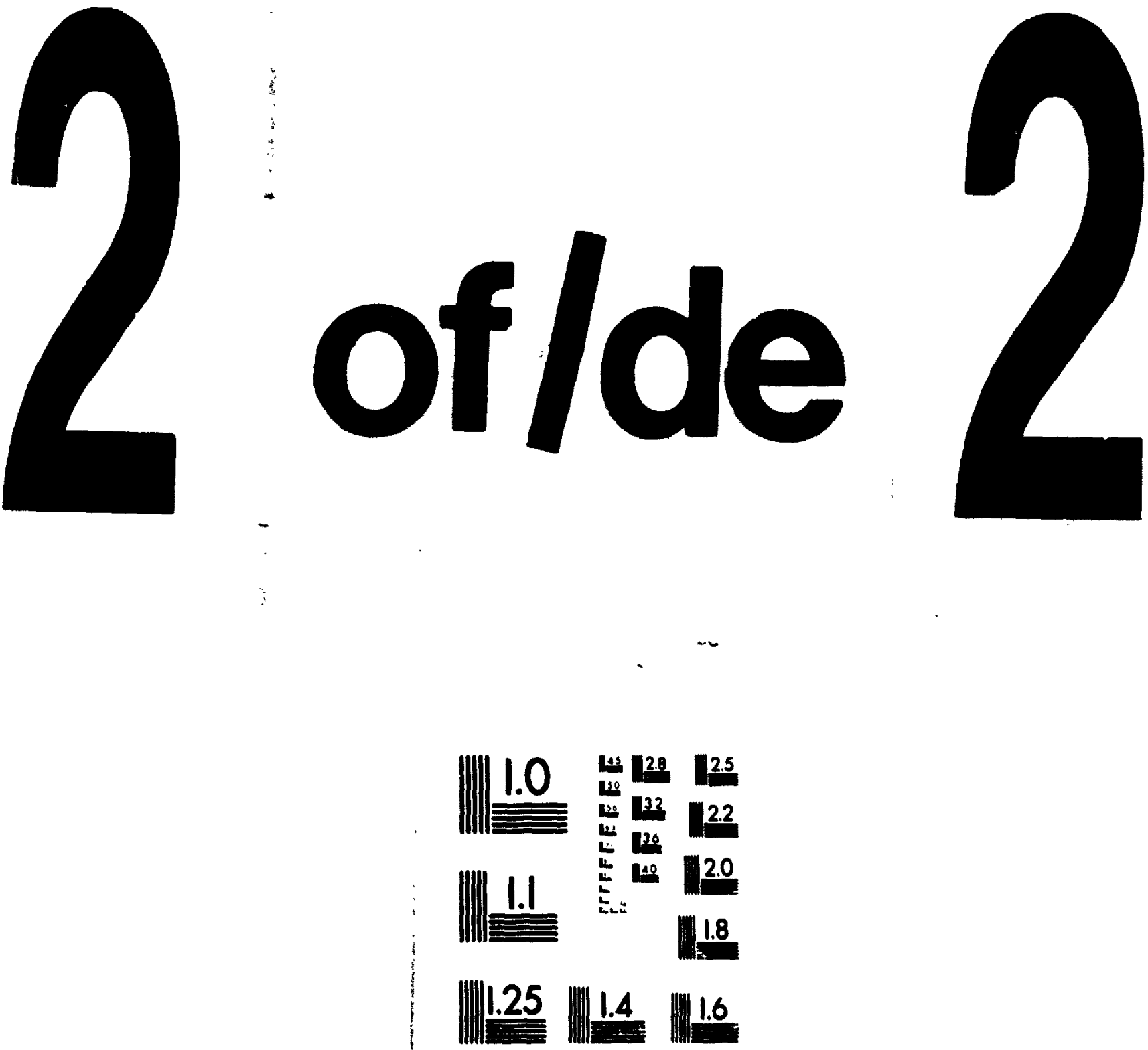

MICROCOPY RESCLUTION TEST CHART

NATIONAL BUREAU OF STANDARDS

STANDARD REFERENCE MATERIAL 1010

(ANSI and ISO TEST CHART NO 2) 
Table 3.2. Means ( $\pm \mathrm{SE}$ ) of weekly incubation mass of female goldencyes nesting on wetlands differing in quality.

\section{Habitat Type}

Isolated with fish

Isolated tishless

Clustered Fishless

Week

$(\underline{N}=4)$

$(\underline{N}=3)$

$(\underline{N}=\underline{5})$

1

$116.1 \pm 0.4$

$119.1 \pm 2.7$

$117.1 \pm 1.3$

2

$110.2 \pm 1.2$

$114.0 \pm 1.6$

$110.5 \pm 1.1$

3

$107.8 \pm 2.1$

$105.9 \pm 1.4$

$1115.4 \pm 1.1$

4

$104.6 \pm 1.3$

$104.4 \pm 1.3$

$102.0 \pm 0.5$ 
While habitat quality can have significant effects on incubation weight changes, female quality may also affect the pattern of weight loss. Goldeneyes that were heavier prior to laying had the largest clutches (Chapter Two) and were also significantly heavier at the initiation of incubation ( $\underline{r}=0.80, \underline{N}=24, \underline{P}<0.001, \underline{N}=24)$, suggestiilg that females in the best condition during prelaying were also in the best condition during incubation, at least for the early stages. However, female mass at the initiation of incubation was uncorrelated with the amount of mass loss during incubation $\left(\underline{r}_{s}=0.33, \underline{N}=9, \underline{P}=0.34\right)$

\section{Hatching success}

Although habitat quality affected female reproductive behaviour, this effect did not influence hatching success (ANOVA; $\underline{F}=0.5, \mathrm{df}=3.35, \underline{P}=0.60$; Table $3-3$ ). Hatching success was also unaffected by the number of eggs in the clutch $(\underline{r}=0.22, \underline{N}$ $=39, \underline{P}=0.20)$. Note that these analyses do not consider clutch loss due to predation or abandonment. None of 14 nest attempts on isolated wetlands where a feriale began incubation were lost, while 10 of 36 nest attempts on clustered wetlands were lost, primarily due to abandonment. Thus, nest loss was more common on clustered wetlands (Fisher exact test, $\mathrm{P}<0.03$ ). 
Table 3-3. Mean ( $\pm \mathrm{SE}$ ) hatching success of clutches (that hitched att least onte egy) on wetlands of differing quality. Data presented are for clutches observed between 1988 and 1990 .

Wetland Type

Sample Size

Hatching Success ("i)

Isolated, containing tish

6

$88.9 \pm 6.8$

Isolated, lacking fish

9

$77.6 \pm 5.8$

Clustered, containing fish

7

$84.3 \pm 7.3$

Clustered, lacking fish

17

$83.4 \pm 4.0$ 


\section{Discussion}

In support of my predictions, nesting habitat quality affected nest attentiveness and the pattern of weight change of incubating female common goldeneyes. I found no evidence that female quality directly influenced incubation constancy or weight change, a result consistent with the findings of Lumsden (unpubl. MS). Female goldeneyes nesting on clustered, fishless wetlands spent the greatest amount of time each day incubating their eggs, and hatched their eggs while in relatively poorer physical condition than females nesting on isolated wetlands. However, habitat quality had no influence on hatching success.

To incubate a clutch successfully, a female must schedule her time on the nest so that the probability that the clutch will hatch is maximized, while the female's survival costs due to declining physical condition are minimized (Cartar and Montgomerie 1987). Higher nest attentiveness usually results in a shorter incubation period (Ricklefs and Smeraski 1983), but this reduces the opportunities for the parent to forage and maintain its body condition. Without sufficient food during incubation. female waterfowl can deteriorate physically or die if weight loss exceeds a minimum critical mass (Korschgen 1977, Ankney and MacInnes 1978, Gatti 1983). Therefore, females that complete incubation in poorer physical condition take greater risks to successfully hatch their clutch, and thus invest relatively more in their current reproductive attempt. When on incubation recesses, female goldeneyes at Wanapitei rarely feed on the nesting wetland (M. Mallory, pers. obs.). Since tishless wetlands usually have more abundant food resources than wetlands containing fish (Eriksson 1983) and are 
preferred foraging sites (Eriksson 1979a, 1983. Chapter One). females nesting thuser Io these sites should require relatively less time to acquire sulficient fond for self maintenance (assuming that all female goldeneyes forage with roughly equivalent efficiency). For this reason, I expected female goldeneyes to adjust their incubatiun behaviour in response to the quality of their nesting wetland. Female goldeneyes nesting on clustered, tishless wetlands averaged higher nest attentiventess than felliales on other wetlands, spent a similar amount of time on the nest each day throughuut incubation, but completed incubation in relatively poor physical condition than females on isolated wetlands. Poor condition at the beginning of brood-rearing maly be less critical for these females because travel distances to rearing wetlands would be short. and body condition could be quickly replenished on high quality wetlands near th: ne:st site. However, by maintaining high nest attentiveness, females on clustered, fishless wetlands may reduce the length of their incubation period (although I lacked sufficient data to test this hypothesis). A shorter incubation period would reduce the opportunities for predators to find and destroy the clutch, and wi. id increatsc tite amount of time ducklings would have to teed and prepare for tledging. Conldeneyes nesting on isolated wetlands had a different incubation pattern. These females were less attentive to their nests than females on clustered wetlands, and attentiveness decreased as incubation proceeded. However, they completed incubation in better physical condition than other goldeneyes. Because these hens nested on isolitted wetlands, they would have to travel a relatively longer distance to reach broud-rearing wetlands. In anticipation of having to move their broods, these females may have 
assessed the risks associated with travelling in poorer physical concition as greater than the risks of slightly increasing the incubation period (due to lower nest attentiveness). and thus maintained better condition.

While my predictions that habitat quality would affect nest attentiveness and weight change were supported, my prediction that the scheduling of incubation rhythms would differ was not supported. Flying to feed during incubation recesses and frequent reheating of eggs are energetically costly, so incubation is more efficient if recesses are taken less frequently but for a longer duration (Drent 1973). I expected females nesting on isolated wetlands to compensate for the energetic costs associated with longer travelling distances (Wooley and Swen 1978) by taking fewer hut longer recesses, as has been demonstrated for black ducks (Anas rubripes: Ringelman et al. 1982) and ring-necked ducks (Aythya collaris; Hohman 1986b). Fenales nesting on isolated wetlands tended to take longer recesses than female goldeneyes nesting on clustered wetlands, but took similar numbers of trips each day, thereby providing less efficient incubation. This result might have been expected if females nesting on isolated wetlands initiated incubation in poorer condition, but this was not the case (Chapter One). If clutches laid on isolated wetlands are less valuable (because offspring survival is lower [Ball et al. 1975. Eriksson 1979a, Talent et al. 1983]), female goldeneyes using isolated wetlands may have adopted an incubation rhythm suitable for maintaining their physical condition.

It is important to note that, despite these differences in incubation behaviour, I found no difference in hatchıng success of females nesting on wetlands of differing 
quality, nor was there any indication that wetland quality affected female sursmal (c).!. none died on the nest). Presumably all females nesting at Wamaipitci were oproum!n! above the minimum performance level required to put clutches at risk. Nonctheless. under more extreme environmental conditions, the observed differences in incuhation behaviour may contribute to differential success.

Female goldeneyes that selected nest sites on clustered, fishless wetlands invested relatively more time and physical resources in producing (Chapter Twol) and incubalting their clutch. The potential risks of decreased survival due to increalsed resource allocation in any single clutch (e.g. Dow and Fredga 1984) may have heen reduced because a reliable, abundant food supply for the female and her ducklings wis nearby. Since it appears advantageous to nest on high yuality wetlands. it is unclear why mally nest sites on these types of wetlands remained unoscupied while bises on isolited wetlands containing tish were used (Chapter One). Previous studies hatve demomstralted that goldeneyes can assess the success of prior clutches in a nest box by prospecting in the previous year (Dow and Fredga 1985, Eadie and Gauthier 1985). Competitively inferior females may choose isolated wetlands because total clatch loss. which is citten the result of nest site comp. ion and/or nest parasitism, is much more common on clustered wetlands. Thus, nesting on isolated wetlands may be better for some femile goldeneyes, because the reproductive cost of losing an entire clutch 10 a species thall rarely renests (Zicus 1990 ) is considerably greater than the potential of reduced success. 


\section{General Discussion}

Acid precipitation and its associated effects on aquatic ecosystems have been linked to the mortality of many aquatic biota, particularly tish (Beamish and Harvey 1972. Beamish 1974). The loss of tish from acidic wetlands allows ayuatic invertehrate populations to flourish (Eriksson 1984). Because breeding female common goldeneves are insectivorous, they appear to dssess tishless habitats as higher quality. Prior to incubation, common goldeneyes forage almost exclusively on tishless wetlands. and prefer these habitats for nesting (Chapter One). Female goldeneyes that possess larger nutrient reserves prior to egg-laying and/or females that nest on fishless wetlands lay clutches of greater mass (Chapter Two). Variations in reproductive effort are achieved by adjusting clutch size, so females allocating more resources to egg production produce more offspring at hatching. Goldeneyes that nest on clustered. tïshless wetlands are more attentive to their nests during incubation and begin brood-rearing in relatively poorer physical condition than goldeneyes nesting on isolated wetlands (Chapter Three). Thus, female goldeneyes nesting on clustered, fishless wetlands invest the most time and resources in a breeding attempt. If goldeneye ducklings survive better on fishless wetlands, then females producing and rearing broods on these sites will have greater annual reproductive success. Because goldeneyes appear to benefit by nesting on high quality wetlands, it is surprising that females in the best condition prior to laying do not acquire nest sites on the best wetlands (Chapter One). Possibly temale mass alone may not be an accurate index of competitive ability, and thus competitively superior females may have actually acquired the best sites. Alternatively, some goldeneyes may have 
chosen sites with less abundant food resources to minimize the risk of complete ilutich loss caused by nest site competition for peferred sites (Chapter Threc).

Should those responsible for producing acid precipitation find comsolatum III these results". Clearly th - answer is "NO". First, my results dellit! mech.mmsms hy which temale goldeneyes adjust parental investment in responsc to alk-maluid hahll.t changes, but they do not demonstrate that female goldeneyes produce more young thit reach independence or that are recruited to the population. Thus, a study (In hrous survival and goldeneye recruitment in relation to breeding habitat quality would he necessary to confïm this hypothesis. Second, any apparent short-term hentetits to insectivorous waterfowl hardly compensatte for the obvious negattise effects on piscivorous aquatic birds (e.g. common loons and common mergansers) and most aquatic biota (reviewed in McNicol et al. 1987). Most importantlv, while goldenẹes appear to take advantage of the apparently suitable habitat creiticed by alcid precipitation, they may experience several more subtle, long-term effects that could adversely affect populations. For example, acidic wetlands at Wanapitci alrcialy likch many acid-sensitive invertebrate taxa (Bendell and MoNicol unpubl. MS). sume of which may be valuable sources of essential nutrients such as calcium (reviewed in Blanclicr and McAuley 1987). Lower survival of juvenile ring-necked ducks reared an acidic wetlands was attributed to reduced prey abundance and quality (McAliky and l.ongcore 1988), as was impaired reproductive performance of dippers breeding in Wales (Ormerod in press) and passerines breeding in the Netherlands (Drent and Woldendurp) 1989). Further investigation is required to determine if goldeneye ducklings reired on 
acidic, fishless wetlands could he similarly affected. As well. if wetlands become increasingly acidic, many other invertebrate taxa will be lost. Mallory et al. (unpubl. MS) demonstrated that some goldeneyes may assess wetland quality based on the presence or absence of tish. As invertebrate abundance (or quality) in tishless wetlands declines in the future, goldeneyes using this technique to choose nest sites will be adversely affected. Finally, goldeneyes breeding on acidic, tishless wetlands could he directly affected by higher concentrations of toxic heavy metals (e.g. aluminum, cadmium) as suggested by Eriksson (1984). Nyholm (1981) attributed impaired breeding in many Scaındinavian passerines to increased uptake of aluminum from invertebrate prey inhabiting acidic wetlands.

In summary, breeding common goldeneyes appear to adjust their reproductive effort and behaviour to take advantage of suiable habitat created by wetland acidification. These investment decisions may result in higher annual reproductive success, but the long-term effects of breeding on acidic, fishless wetlands remain to be examined. 


\section{Literature Cited}

Afton, A. D. 1979. Time budget of breeding Northern Shovel:rs. Wilsun Bull. "1: 4249.

Afton, A. D. 1980. Factors affecting incubation rhythms of Northern Shovelers. Condor 82: 132-137.

Afton, A. D., and R. D. Sayler. 1982. Social courtship and pairhonding of commmon goldeneyes, Bucephala clangula, wintering in Minnesota. Cim. Field Natt. Wh: 295-300).

Ainley, D. G. and D. P. DeMaster. i980. Survival and mortality in a population af Adelie Penguins. Ecology 61: 522-530.

Aldrich. T. W., and D. G. Raveling. 1983. Effects of experience and hody " wiglth un incubation behavior of Canadal Geese. Auk 100): 67(1)-67\%.

Alvo, R., D. J. T. Hussell, and M. Berrill. 1988. The breeding success of common loons (Gavia immer) in relation to alkalinity and other lake characteristics in Ontario. Can. J. Zool. 66: 746-752.

Amurdsen. T., and J. N. Stokland. 1990. Egg size and parental quality intluence nestling growth in 'he Shag. Auk 107: $+110-413$.

Anderson, M. G. 1984. Parental iivestment and pair-bond hehavior among canvashack ducks (Aythya vallisineria, Anatidae). Behav. Ecol. Sociobiol. 15: 81-91).

Ankney, C. D., and C. D. Macinnes. 1978. Nutrient reserves and reproductive performance of female Lesser Snow Geese. Auk 95: 45\%.471. 
Ankney, C. D., and A. D. Afton. 1988. Bioenergetics of breeding Northern Shwelers: diet, nutrient reserves. clutch size, and incubation. Condor 91): 459.472.

Arcese, P., and J. N. M. Smith. 1988. Effects of population density and supplemental foud on reproduction in song sparrows. J. Anim. Ecol. 57: 119.136.

Ball, I. J., D. S. Gilmer, L. M. Cowardin, and J. H. Reichmann. 1975. Survivall of Wood Duck and Mallard broods in north-central Minnesota. J. Wild. Manage. 39: $776-780$.

Bailey, S. R. and H. Milne. 1982. The influence of female age on breeding in the eider Somateria mollissimil. Bird Study 29: 55-66.

Beamish, R. J. 1974. The loss of tish populations from unexploited remote lakes in Ontario, Canadal as a consequence of atmospheric tallout of acid. Water Res. \&. 85.95.

Beamish. R. J., and H. H. Harvey. 1972. Aciditication of the La Cloche Mountain lakes, Ontario and resulting tish mortalities. J. Fish. Res. Bd. Can. 29: 1131 1143.

Bellrose, F. C. 1981). Ducks, geese, and swans of North America. Stackpole Books, Harrisburg, Pennsylvania.

Bendell, B. E., and D. K. McNicol. 1987a. Fish predation, lare acidity and the composition of aquatic insect assemblages. Hydrobiologia 150: 193-202.

Bendell, B. E. and D. K. McNicol. 1987b. Cyprinid assemblages, and the physical and chemical characteristics of small northern Ontario lakes. Environ. Biol. Fishes 19: 229.234 . 
Bendell, B. E., and D. K. McNicol. unpubl. MS. Duckling diet and invertebrate furd resources with respect to fish and lake acidity.

Bengston, S. -A. 1971. Variations in clutch size in ducks in relation to the ford supply. Ibis 113: 523-526.

Blancher, P. J., and D. G. McAuley. 1987. Influence of wetland acidity on asian breeding success. Trans. 52nd N. A. Wildl. Nat. Res. Conf. pp. 628-(1.3.5.

Blanchei, P. J., and D. K. McNicol. 1988. Breeding hiology of tree swallows in relation to wetland acidity. Can. J. Zool. 66: 842-849.

Boag, P. T., and A. J. van Noordwijk. 1987. Quantitative genetics. In: Avian genetics: a population and ecological approach (F. Cooke and P. A. Buckley, eds.). Academic Press, London. pp. 45-78.

Brockelman, W. Y. 1975. Competition, the titness of oftspring, and optimal clutch size. Am. Nat. 109: 677-699.

Campbell, P. G. C., and P. M. Stokes. 1985. Acidification and toxicity of metals to aquatic biota. Can. J. Fish. Aquatt. Sci. 42: 2(134-2(14\%.

Cartar, R. V., and R. D. Montgomerie. 1987. Daly-to-day variation in nest attentiveness of white-rumped sandpipers. Condor 89: 252.261).

Charnov, E. L., and J. R. Krebs. 1974. On clutch size and titness. Ibis 116: 217-21\%.

Cooper, J. A. 1978. The history and breeding biology of the Canada Geese of Marshy Point, Manitoba. Wildl. Monogr. No. 61.

Danell, K., and K. Sjoberg. 1977. Seasonal emergence of chironomids in relation (o) egg-laying and hatching of ducks in a restored lake (northern Sweden). Wildiowl 
28: $129-135$.

Dawkins, R., and T. R. Carlisle. 1976. Parental investment, mate desertion, and a fallacy. Nature 262: 131-133.

DesGranges, J. L., and M. Darveau. 1985. Effect of lake acidity and morphometry on the distribution of aquatic birds in southern Quebec. Holarct. Ecol. 8: 181-190.

DesGranges, J. L. 1989 . Studies of the effects of aciditication on aquatic wildlite in Canada: lacustrine hirds and their habitats in Quebec. Can. Wildl. Serv. Occ. Pap. No. 67.

Dijkstra, C., S. Daan. T. Meijer, A. J. Cave, and R. P. B. Foppen. 1988. Daily and seasonal variations in body mass of the kestrel in relation to fond availability and reproduction. Arde:i 76: 127-140.

Dow, H., and S. Fredga. 1984. Factors affecting reproductive output of the Goldeneye Duck Bucephala clangula. J. Anim. Ecol. 53: 679-692.

Dow, H., and S. Fredga. 1985. Selection of nest sites by a hole-nesting duck, the Goldeneye Bucephala clangula. Ibis 127: 16-30.

Drent. R. H. 1973. The natural history of incubation. In: Breeding biology of hirds (D. S. Farner, ed.). National Academy of Sciences, Washington. pp. 262-311.

Drent, R. H., and S. Daan. 1980. The prudent parent: energetic adjustments in arian hreeding. Ardea 68: 225-252.

Drent. P. J., and J. W. Woldendorp. 1989. Acid rain and eggshells. Nature 339: 431.

Drobney, R. D. 1980). Reproductive bioenergetics of Wood Ducks. Auk 97: 48(1-49().

Drobney, R. D. 1982. Body weight and composition changes and adaptation for 
breeding in Wood Ducks. Condor 84: 30()-305.

Eadie, J. McA., and A. Keast. 1982. Do goldeneye and perch compete for lioul! Oecologia 55: 225.230.

Eadie, J. McA., and G. Gauthier. 1985. Prospecting for nest sites by cilvity-nesting ducks of the genus Bucephala. Condor 87: 528-534.

Eadie, J. McA., and H. G. Lumsden. 1985. Is nest parasitism alwalys deleterious II goldeneyes? Am. Nat. 126: 859-866.

Eadie, J. McA., F. P. Kehoe, and T. D. Nudds. 1988. Pre-hatch and post-hatch brond amalgamation in North American Anatidae: a review of hypotheses. Cinl. J. Zool. 66: 1709-1721.

Eldridge, J. L., and G. R. Krapu. 1988. The influence of diet quality on clutch size :in laying pattern in mallards. Auk 105: 102-110.

Eriksson, M. O. G. 1976. Food and feeding habits of downy Goldeneye Bucephlialia clangula (L.) ducklings. Ornis Scind. 7: 159-16\%.

Eriksson, M. O. G. 1978. Lake selection by Goldeneye ducklings in relation to the abundance of food. Wildfowl 29: 81-85.

Eriksson, M. O. G. 1979a. Aspects of the breeding biology of the goldeneye Bucephala clangula. Holarct. Ecol. 2: 186-194.

Eriksson, M. O. G. 1979b. Competition between freshwater fish and Goldeneyes (Bucephala clangula) for common prey. Oecologia 41: 9\%-107.

Eriksson, M. O. G. 1983. The role of fish in the selection of lakes by non-piscivorous ducks: Mallard, Teal, and Goldeneye. Wildfowl 34: 27-32. 
Eriksson, M. O. G. 1984. Acidification of lakes: effects on waterbirds in Sweden.

Ambio 13: 260-262.

Eriksson, M. O. G., L. Henrikson, B. I. Nilsson, G. Nyman, H. G. Oscarson, and A. E. Stenson. 1980. Predator-prey relations important for the biotic changes in acidified lakes. Ambio 9: 248-249.

Gauthier, G. 1988. Factors affecting nest box use by buftleheads and other cavitynesting birds. Wildl. Soc. Bull. 16: 132-141.

Gatti, R. C. 1983. Incubation weight loss in the mallard. Can. J. Zool. 61; 565-569.

Glooschenko, V., P. J. Blancher, J. Herskowitz, R. Fulthorpe. and S. Rang. 1986.

Association of wetland acidity with reproductive parameters and insect prey of the eastern kinghird (Tyrannus tyrannus) near Sudbury, Ontario. Water Air Soil Pollut. 30: 553-567.

Hailman, J. P. 1986. The heritability concept applied to wild birds. Current Ornith. 4: $71-95$

Haines, T. A. 1981. Acidic precipitation and its consequences for aquatic ecosystems: a review. Trans. Am. Fish. Soc. 110: 669-707.

Hepp, G. R. 1984. Dominance in wintering Anatinae: potential effects on clutch size and time of nesting. Wildfowl 35: 132-134.

Hepp, G. R., D. J. Stangohr, L. A. Baker, and R. A. Kennamer. 1987. Factors affecting variation in the egg and duckling components of wood ducks. Auk 104: 435.443.

Hogstedt, G. 1980. Evolution of clutch size in birds: adaptive variation in relation to 
territory quality. Science 210: 1148-1150.

Högstedt, G. 1981. Effect of additional food on reproductive success in the malypic (Pica pica). J. Anim. Ecol. 50: 219-229.

Hohman, W. L. 1986a. Changes in body weight and body composition of breding Ring-necked Ducks (Avthval collaris). Auk 103: 181-188.

Hohman, W. L. 1986b. Incubation rhythms of Ring-necked Ducks. Condur \$8: 2011296.

Hörnfeldt, B., and U. Eklund. 1990. The effect of food on liaving date and clutch size in Tengmalm's Owl, Aegolius funereus. Ihis 132: 395-4116.

Hunter, M. L., Jr., J. J. Jones, K. E. Gibbs, and J. R. Moring. 1986. Duckling responses to lake acidification: do black ducks and fish compete? Oikus 47: 2632.

Jeffries, D. S. 1984. Atmospheric deposition of pollutants in the Sucibury areat. In: Environmental impacts of smelters (J. O. Nriagu, ed.). John Wiley and Suns, New York. pp. 117-154.

Johnsgard, P. A. 1973. Proximate and ultimate determinants of clutch size in Anatidae. Wildfowl 24: 144-149.

Jones, G. 1987. Time and energy constraints during incubation in free-living swillows (Hirundo rustica): an experimental study using precision electronic balances. J. Anim. Ecol. 56: 229-245.

Kear, J. 1970. The adaptive radiation of parental care in waterfowl. In: Social behaviour in birds and mammals (J. H. Crook, ed.). Academic Press, New York. 
pp. 357-392.

King, J. R. 1973. Energetics of reproduction in birds. In: Breeding biology of hirds (D. S. Farner, ed.). National Academy of Sciences, Washington. pp. 78-107.

Klomp, H. 1970. The determination of clutch size in birds. A review. Ardea 58: 1. 124.

Korschgen, C. E. 1977. Breeding stress of female eiders in Maine. J. Wildl. Manage. 41: $360-373$.

Krapu, G. L. 1981. The role of nutrient reserves in mallard reproduction. Auk 98: 29-38.

Krapu, G. L., and H. A. Doty. 1979. Age-related aspects of Mallard reproduction. Wildfowl 30: 35-39.

Lack, D. 1967. The significance of clutch size in waterfowl. Wildfowl 18: 125-128. Leblanc, Y. 1989. Variation in size of eggs of captive and wild Canada Geese. Ornis Scand. 20: 93-98.

Lumdsen, H. G. unpubl. MS. Changes in body mass of goldeneyes and their implications.

Lumsden, H. G., and R. Wenting. 1976. Common goldeneyes hatching trom cracked eggs. Auk 93: 833-835.

Lumsden, H. G., R. E. Page, and M. Gauthier. 1980. Choice of nest boxes by Common Goldeneye in Ontario. Wilson Bull. 92: 497-505.

Macinnes, C. D., R. A. Davis, R. N. Jones, B. C. Lieff, and A. J. Pakulak. 1974. Reproductive efficiency of McConnell River small Canada Geese. J. Wildl. 
Manage. 38: 686-707.

Mallory, M. L., P. J. Blancher, P. J. Weatherhead, and D. K. MiNicol. unpull. MIS.

Presence or absence of fish as a cue to macroinvertebrate abundance in hurceal wetlands.

McAuley, D. G., and J. R. Longcore. 1988. Survival of juvenile ring-necked ducks on wetlands of different pH. J. Wildl. Manage. 52: 169.176.

McNicol, D. K., B. E. Bendell, and R. K. Ross. 1987. Studies of the effects of acidification on aquatic wildlife in Canada: waterfowl and trophic relationships in small lakes in northern Ontario. Can. Wildl. Serv. Occals. Pap. No. 12.2.

Montgomerie, R. D., and P. J. Weatherhead. 1988. Risks and rewards of nest defince by parent birds. Quart. Rev. Biol. 63: 167-187.

Naylor, B. J., and J. F. Bendell. 1989. Clutch size and egg size of spruce grouse in relation to spring diet, food supply, and endogenous reserves. Can. J. Zool. 67: 969-980.

Noyes, J. H., and R. L. Jarvis. 1985. Diet and nutrition of breeding female redheial and Canvasback ducks in Nevada. J. Wildl. Manage. 49:: 2013-211.

Nudds, T. D. 1980. Canvasback tolerance of redhead parasitism: an observation and an hypothesis. Wilson Bull. 92: 414.

Nyholm, N. E. I. 1981. Evidence for involvement of aluminum in catusation of defective formation of eggshells and impaired breeding in wild passerine birds. Env. Res. 26: 363-371.

Nyholm, N. E. I., and H. E. Myhrberg. 1977. Severe eggshell delects and impaired 
reproductive capacity in small passerines in Swedish Lapland. Oikos 29: 336-341. O'Halloran, J., S. D. Gribbin, S. J. Tyler, and S. J. Ormerod. 1990. The ecology of dippers Cinclus cinclus (L.) in relation to stream acidity in upland Wales: timeactivity budgets and energy expenditure. Oecologia 85: 271-280.

Ormerod, S. J., K. R. Bull, C. P. Cummins, S. J. Tyler, and J. A. Vickery. 1988. Egy mass and shell thickness in Dippers Cinclus cinclus in relation to stream acidity in Wales and Scotland. Environ. Pollut. 55: 107-121.

Ormerod, S. J., J. O'Halloran, S. D. Gribbins, and S. J. Tyler. in press. The ecology of dippers Cinclus circlus (L.) in relation to stream acidity in upland Wales: breeding performance, cacium physiology, and nestiling growth. Ecology.

Perrins, C. M. 1977. The role of predation in the evolution of clutch size. In: Evolutionary Ecology (Stonehouse, B. and C. M. Perrins, eds.). Macmillan Publishing, London. pp. 181-191.

Peterson, S. R., and R. S. Ellarson. 1979. Changes in Oldsquaw carcass weight. Wilson Bull. 91: 288-300.

Pitblado, J. R.. W. Keller, and N. I. Conroy. 1980. A classification and description of some northeastern Ontario lakes influenced by acid precipitation. J. Great Lakes Res. 6: 247.257.

Rahn, H., C. V. Palganelli, and A. Ar. 1975. Relation of avian egg weight to body weight. Auk 92: 750-765.

Rattner, B. A., G. M. Haramis. D. S. Chu, and C. M. Bunck. 1987. Growth and physiological condition of black ducks reared on acidified wetlands. Can. J. Zool. 
65: $2953-2958$.

Raveling, D. G. 1979. The annual cycle of hody composition of Calladal (icesce with special reference to control of reproduction. Auk $\%(2: 234-252$.

Reinecke, K. J., T. L. Stone, and R. B. Owen, Jr. 1982. Staisumal carcalss compunimun and energy balance of female Black Ducks in Maine. Condur 84: $42(1)-42(1$.

Ricklefs, R. E. 1974. Energetics of reproduction in birds. In: Avian energetics (R. A. Paynter, Jr., ed.). Nuttall Ornithol. Club, Cambridge, Mass. pp. 152-192.

Ricklefs, R. E., and C. A. Smeraski. 1983. Variation in incubation period within a population of the European Starling. Auk 100: 926-931.

Ringelman, J. K., J. R. Longeore, and R. B. Owen, Jr. 1982. Nest and hrood attentiveness in temale Black Ducks. Condor $84: 1111.116$.

Rohwer, F. C. 1988. Inter- and intraspecific relationships between egg size and clutch size in waterfowl. Auk 105: 161-176.

Rohwer, F. C., and M. G. Anderson. 1988. Female-biased philopantry, monngaimy, and the timing of pair formation in migratory waterfowl. Current Ornithol. 5: 18?. 221.

Savard, J.P. 1984. Territorial behaviour of Common Goldeneye, Barrows Cioldeneye and Bufflehear' in areas of sympatry. Ornis Scand, 15: 211.216.

Savard, J.-P. 1988. Winter, spring and summer territoriality in Barrow's Cioldencye: characteristics and benefits. Ornis Scand. 19: 119.128.

Semel, B., P. W. Sherman, and S. M. Byers. 1988. Effects of brond parasitism and nest-box placement on Wood Duck breeding ecolugy. Condor 9(): 92()-931). 
Slagsvold, T., and J. T. Lifjeld. 1988. Ultimate adjustment of clutch size to parental feeding capacity in a passerine bird. Ecology 69: 1918-1922.

Siagsvold, T., and J. T. Lifjeld. 1991). Influence of male and female quality on clutch size in tits (Parus spp.). Ecology 71: 1258-1266.

Smith, C. C., and S. D. Fretwell. 1974. The optimal balance between size and number of offspring. Am. Nat. 108: 499-506.

Sugden, L. G., and H. J. Poston. 1968. A nasal marker tor ducks. J. Wildl. Manage. 32: $984-986$.

Talent, L. G., R. L. Jarvis, and G. L. Krapu. 1983. Survival of Mallard broods in south-central North Dakota. Condor 85: 74-78.

Thumpson, S. C., and D. G. Raveling. 1987. Incubation behavior of emperor geese compared with other geese: interactions of predation, body size and energetics. Auk 104: 707-716.

Titman, R. D. 1981. A time-activity budget for breeding mallards (Anas platyrhunchos) in Manitoba. Can. Field Nat. 95: 266-271.

Toft. C. A., D. L. Trauger, and H. W. Murdy. 1984. Seasonal decline in brood sizes of sympatric waterfowl (Anas and Aythya, Anatidae) and a proposed evolutionary explanation. J. Anim. Ecol. 53: 75-92.

Tome, M. W. 1984. Changes in nutrient reserves and organ size of female Ruddy Ducks breeding in Manitoba. Auk 101: 830-837.

Trivers, R. L. 1972. Parental investment and sexual selection. In: Sexual selection and the descent of man 1871-1971 (B. Campbell, ed.). Aldine, Chicago. pp. 136-179. 
Wooley, J. B., and R. B. Owen. Jr. 1978. Energy costs of altivity alld datily clllet!! expenditure in the Black Duck. J. Wildl. Manage. 42: 739.745.

Wooller, R. D. and J. C. Coulson. 1977. First breeding of Kittiwakes. Ihis 114: 3.3\%. 349.

Zicus, M. C. 1990. Renesting by a common goldeneye. J. Ficld Ornithol. 61: 245-245. 

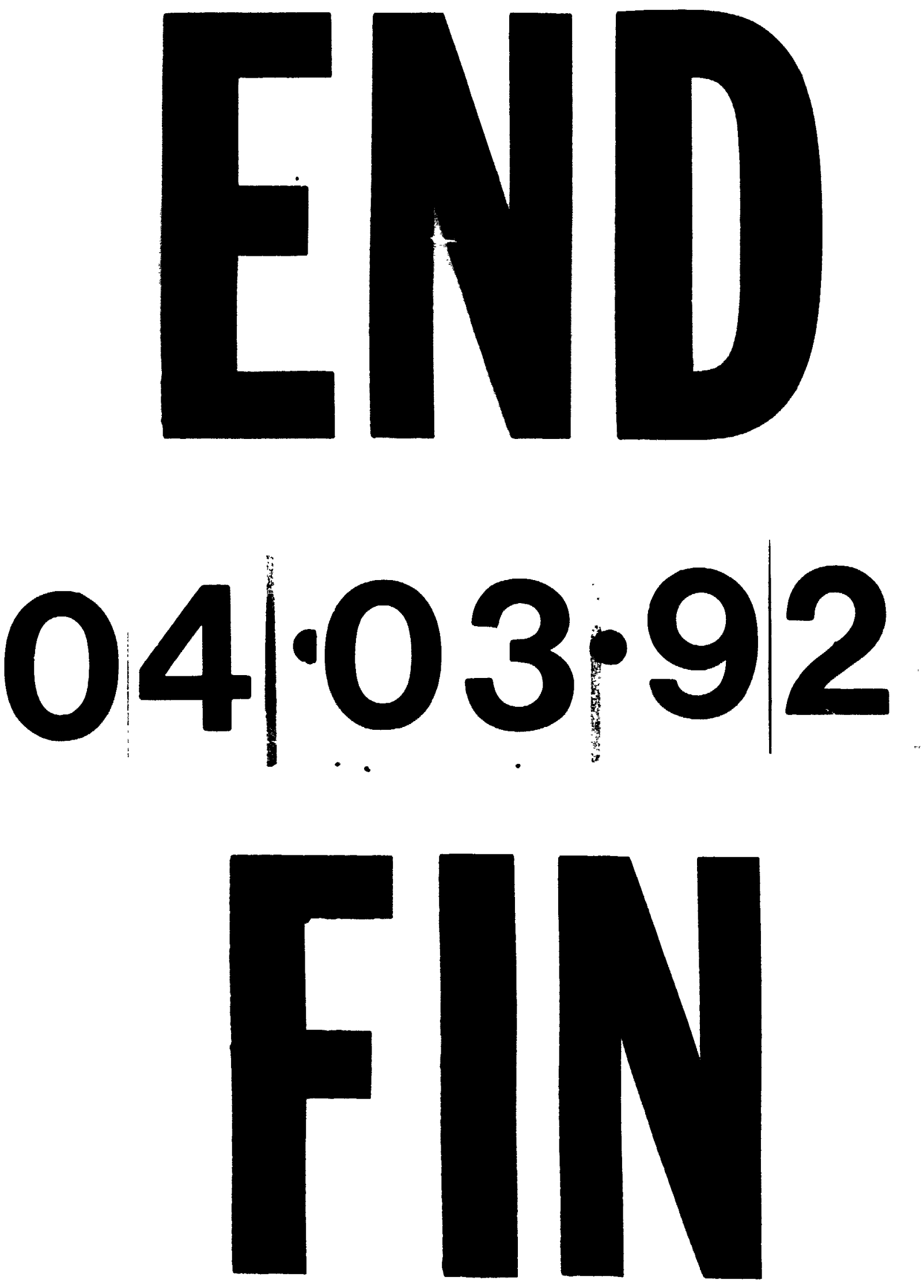